Article

\title{
Thermal Properties of Semolina Doughs with Different Relative Amount of Ingredients
}

\author{
Fabio Fanari ${ }^{1}$, Gianluca Carboni ${ }^{2}$ (), Massimiliano Grosso ${ }^{1, *}$ and Francesco Desogus ${ }^{1}$ ([) \\ 1 Department of Mechanical, Chemical and Materials Engineering, University of Cagliari, 09123 Cagliari, Italy; \\ f.fanari@dimcm.unica.it (F.F.); f.desogus@dimcm.unica.it (F.D.) \\ 2 Agris Sardegna-Agricultural Research Agency of Sardinia, 09123 Cagliari, Italy; gcarboni@agrisricerca.it \\ * Correspondence: massimiliano.grosso@dimcm.unica.it
}

Received: 31 January 2020; Accepted: 11 March 2020; Published: 13 March 2020

\begin{abstract}
The impact of the relative amount of ingredients, wheat variety, and kneading time on the thermal properties of semolina doughs were investigated by means of thermogravimetric analysis (TGA). The doughs were prepared by mixing water, semolina, yeast, and salt in different proportions. The gelatinized flour fraction plays an important role in the thermal properties' definition, while the water amount influences the development of the dough network and, consequently, the starch gelatinization phenomena. Furthermore, the amount of yeast and salt influences the dough network force and, consequently, the thermal properties. The TGA technique was applied in order to evidence the mass loss as a function of the increasing temperature, considering that this behavior depends on the dough network force and extension. In such a way, it was possible to find some information on the relationship between the dough characteristics and the thermogravimetric analysis outputs. The study is devoted to acquiring deeper knowledge about the thermophysical characteristics of doughs in the breadmaking industrial processes, where the controllability and the energy performances need to be improved. A deeper knowledge of the dough properties, in terms of measurable parameters, could help to decrease the amounts of off-specification products, resulting in a much more energy-efficient and sustainable processing.
\end{abstract}

Keywords: breadmaking; doughs; energy performance; ingredients; kneading; salt; semolina; sustainability; thermal properties; yeast

\section{Introduction}

The quality of bread doughs is strongly influenced by the interactions between its ingredients in the presence of water [1]. As a consequence, the mixing process and its settings are important to assess the quality of the end product. Another important factor is the flour composition that can strongly affect the mechanical properties of the dough. The most accurate way addressed in the literature to study dough mechanical properties is rheological characterization. Rheological properties of dough strongly depend on its microstructure [2], mostly consisting of the so-called gluten network, a complex structure that originates from protein hydration [3]. These properties are relevant because they have a strong impact on the final quality of the product.

Another very interesting technique, which can be used to study the interactions among the dough components and their impact on the food microstructure, is the thermogravimetric analysis (TGA). For example, some researchers [4] used this technique to study the effect of operative conditions on the properties of corn tortillas, and others [5] to assess the thermal properties of apple pomace flours. In the field of bread (or pasta) doughs, it is possible to find several applications of this technique, in order to study the effect on the dough thermal properties of some additives [6-8], of the flour particle size [9], of the operative conditions [10], or of some particular flour varieties [11]. 
The dough thermal properties are mainly due to two processes occurring in the dough: Starch gelatinization and protein coagulation [12]. These transformations occur approximately in the same temperature range $\left(55-80^{\circ} \mathrm{C}\right)$ and moisture level [13]. The starch content and related characteristics influence the dough rheological properties, especially upon heating in the presence of water when starch gelatinizes [14]. The gelatinization process causes the transition of insoluble starch granules to a solution composed of individual molecules [15]. Gelatinization of starch is a cooperative process, where structural relations between amorphous and crystalline regions within the starch granules are responsible for the sharpness of the thermal transition and for the temperature at which it occurs [16]. The gelatinization temperature depends on the botanical origin of the starch (some types of unmodified native starches, for example, start swelling at $55^{\circ} \mathrm{C}$, while other types at $85{ }^{\circ} \mathrm{C}$ [17]), but also on the amount of water, on $\mathrm{pH}$, and the kind and concentration of salts, sugars, fats, and proteins in the recipe [18]. The presence of other ingredients and their quantity can influence these parameters because of the competition between starch and proteins for the available water [19,20]. On the other side, protein coagulation is a change in the structure of proteins induced by heat in this case. In this phenomenon, the main role is played by gluten, which is composed of two fractions: The gliadins, which contribute to viscosity, extensibility, and cohesiveness of the dough, and the glutenins, which are responsible for the dough strength and elasticity [21]. The ratio between gliadin and gluten depends on the wheat variety, and it is a very important factor, as if it increases, the elasticity of gluten decreases [22]. The glass transition temperature $(\mathrm{Tg})$ is the main parameter for understanding the mechanical properties of gluten proteins [15]. It is defined as the physical change that occurs during the heating process, between the two equilibrium phases of the proteins: The semi-solid one that prevails at high temperatures, and the glassy-solid one, typical at low-temperature conditions. Proteins and gluten influence the gelatinization parameters of starch and water availability [16] because starch gelatinization and protein coagulation are competitive and antagonistic [23]. The interactions between starch and proteins are a consequence of the attraction between positively and negatively charged colloids in an acidic environment, and the modification of wheat proteins due to heating results in a loss of protein binding to the starch and a decrease of the interactions [24]. Thus, in the presence of gluten proteins, the starch gelatinization peak temperature increases and the enthalpy decreases. In addition, the peak temperature increases as the ratio between gluten and starch increases [24]. The thermal stability of the gluten decreases as the level of gliadins increases and their transition also shifts to lower temperatures; the changes in the starch gelatinization parameters are believed to be due to the reduced amount of available water in the presence of gluten [25].

The amount and the mobility of water are important parameters concerning starch gelatinization, gluten network building, the thermal stability of proteins, and glass transition temperature $[16,25,26]$. Starch and gluten are complex chemical polymers and hence their interaction with water is complex [14], gluten reacts with proteins to build the gluten network, and it is fundamental to hydrate the starch.

Proteins, starch, and water are the main components of dough, but usually, also salt, yeast, and other additives are mixed with them in order to improve the texture and the flavor of the final product. These substances, in turn, influence the rheological and the thermal properties of the dough. In the literature, few studies about the influence of the ingredients on the thermal properties of doughs can be found, except for the effect of salt, mainly due to the interest for the human health problems caused by the excessive use of this ingredient. Some researchers [27] stated that salt enhances strengthening of the proteins harden and helps in conditioning the dough by improving its tolerance to mixing, producing a more stable and stiffer dough, by increasing the apparent viscosity and the glutinic network strength and exalting the portion of solid-like behavior in the dough. The explanation of this can be found in the behavior of salt, which, in a flour-water system, binds with positive charges of proteins, eliminating the repulsion between them and promoting their mutual interactions; this phenomenon leads to the presence of more elongated protein strands instead of less connected protein particles, which results in slower hydration of the proteins, leading to an increase of the dough optimal mixing time [28], but also producing a stronger gluten network [29]. In another study [30], it was found out that proteins 
coagulation, and amylase activity are slowed down by the salt content increasing in the dough, leading to a slowing of the gelatinization process, and also the glass transition temperature is reduced [31]. Other researchers [32] reported that the gelatinization process shows a shift to higher temperatures when $\mathrm{NaCl}$ is added to the dough. However, in these more recent works, the role played by salt on the dough rheological properties is not clear, and the study of the dough thermal properties could be useful to understand how the salt affects the glutinic network building. Regarding the yeast effect on the thermal properties of doughs, there is a lack of information in the literature, and in the previous work, few studies have been carried out [2].

Additionally, the mixing process and its conditions are important to determine the amount of free and binding water because all the interactions among the dough components are established during mixing. An insufficiently developed dough might result in higher free water content because the latter has no sufficient time to react with the flour proteins and with the soluble components in the system. On the other hand, if the kneading process is too strong or too long, it can damage the starch chains or gluten structures. The time required for the optimum dough development is also positively correlated with the polymeric protein composition and the ratio between protein polymers and monomers [27]. Regarding starch, its characteristics are important to define the resistance of the dough, for example, high amylose starches require more energy to break up bonds to gelatinize into starch molecules, leading to a rigid and stiff gel [33].

The aim of this work is to investigate how the relative amount of ingredients, the composition of the semolina, and the mixing time may affect the thermal properties of the dough. In fact, it is known that all these parameters influence the properties of the final product and the process optimal conditions. With this regard, the TGA may reveal to be a powerful tool to study the thermal properties of the dough by measuring its weight reduction caused by heating the sample. The weight reduction of dough is mainly due to water loss and sample degradation. In the literature, two main phenomena, related to dough characterization by means of TGA, are reported: The first one is linked to the loss of easily removable water that undergoes diffusion through the dough matrix to reach the surface and happens around $90^{\circ} \mathrm{C}$. The other one, which occurs at approximately $135^{\circ} \mathrm{C}$, which is attributed to the water more tightly associated with the sample matrix and, consequently, requiring higher temperatures to be removed $[2,4,7,8,34,35]$. Thus, studying these phenomena by the TGA technique, it is possible to characterize some kinds of bonds that are established during the mixing and network building phases and to find information about how the selected parameter influences the dough characteristics [13]. Finally, these results were compared with the rheological properties to establish a possible connection between these two kinds of measurements. The study aims at satisfying the need for deeper knowledge about the thermophysical characteristics of doughs and their influence on rheological properties in relationship with the breadmaking industrial processes, where the controllability and the energy performances need to be monitored and improved [36,37].

\section{Materials and Methods}

For the study of water, salt, and yeast impact, doughs were prepared using commercial re-milled durum wheat semolina with a protein content of about $13 \%$ (properties reported in Table 1), distilled water, commercial baker yeast (Saccharomyces cerevisiae), and commercial iodized salt $(\mathrm{NaCl})$. The dough kneading was performed by means of a mixograph (National Manufacturing, Lincoln, NB) with $10 \mathrm{~g}$ of flour capacity. The impact of water, salt, and yeast were investigated by means of a "one factor-at-a-time" approach. In more detail, a baseline set of levels for all the three factors is selected, and then each factor has been varied along its range with the other factors held constant. The baseline sample was made with $10 \mathrm{~g}$ of semolina, an amount of water of $50 \%$, and without the addition of salt and yeast. Starting from the reference, three groups, each one consisting of three samples, were taken into account: I) Samples, identified with letter "W", made with $10 \mathrm{~g}$ of semolina and an amount of water, based on the semolina weight, of 50\% (W50), 55\% (W55), and 60\% (W60); II) samples, identified with the letter "S", obtained by mixing $10 \mathrm{~g}$ of semolina with $5 \mathrm{~g}$ of water and an amount of salt, based on the semolina 
weight, of $0.5 \%$ (S0.5), $1.5 \%$ (S1.5), and 3.0\% (S3.0); III) samples, identified with letter "Y", constituted by $10 \mathrm{~g}$ of semolina, $5 \mathrm{~g}$ of water and an amount of yeast, based on the semolina weight, of $0.5 \%$ (Y0.5), $1.5 \%$ (Y1.5), and 3.0\% (Y3.0). W50 represents the reference sample because it is prepared with $50 \%$ of the water that hereafter is considered as the reference value and also because it does not contain any salt or yeast. Each dough was kneaded for $20 \mathrm{~min}$ before withdrawing the sample and starting the thermal analysis. This time was identified as the mean optimum development time by considering the optimum time detectable by the mixograph, as this parameter could be different from one dough to another one and affects the thermal properties [38]. The optimum mixograph time is reached when the mixing process and the building of the network are completed, and the strength of the dough results to be the highest. To study the influence of the semolina composition, also two varieties of re-milled semolina from Italian monovarietal durum grains, Alemanno (A) and Cappelli (C), were considered in addition to the commercial semolina (CS) mentioned above. The semolina samples were mixed in the mixograph with water (the quantity of added water was $50 \%$ based on the semolina weight) for three different kneading times: The optimum mixing time ( $2 \mathrm{~min}$ for C, $4 \mathrm{~min}$ for A, $5 \mathrm{~min}$ for CS), half of the optimum time, and twice the optimum time. This choice was made to study the thermal properties of a well (optimally) developed, an undeveloped, and an overdeveloped dough. The optimum time on mixograph corresponds to the optimal kneading time of the sample at which the mixing process and the building of the network are completed, and the strength of the dough results to be the highest. The properties of the semolina under study (protein, gluten content, and gluten index) are reported in Table 1. The gluten index (G.I.) is a parameter providing information on both gluten quality and gluten quantity, and it expresses the weight percentage of the wet gluten remaining on a sieve after automatic washing with salt solution and centrifugation [39]. The main method applied in the measurement of G.I. is the AACC Int. 38-12A or ICC Standard method 137-1 [40]. The gluten index works as a criterion defining whether the gluten quality is weak (G.I. $<30 \%$ ), normal (G.I. between 30 and $80 \%$ ), or strong (G.I. > 80\%) [41]. Different kinds of wheat with a similar protein content can be classified according to the G.I. value. In other words, the G.I. is related to the protein network strength.

Table 1. Properties of semolina under study.

\begin{tabular}{cccc}
\hline & Proteins (\%) & Gluten (\%) & Gluten Index (\%) \\
\hline Alemanno (A) & $11.8^{*}$ & 7.3 & 47.12 \\
Cappelli (C) & $11.2^{*}$ & 6.9 & 37.32 \\
Commercial (CS) & $11.7^{* *}$ & 8.7 & 88.00 \\
\hline
\end{tabular}

${ }^{*}$ measured on the grain; ${ }^{* *}$ measured on the semolina.

The composition (\% of each ingredient, semolina variety, and the mixing time) are summarized in Table 2. For each sample, a small quantity (about $100 \mu \mathrm{g}$ ) of dough (prepared just before) was put into an alumina crucible and inserted into the TGA device (TA Instruments, SDT-Q600), then the sample was heated up to $600{ }^{\circ} \mathrm{C}$ with a temperature ramp of $5{ }^{\circ} \mathrm{C} / \mathrm{min}$. For each run, the weight loss of the sample was registered, and then the percentage reduction and the derivative of the latter with respect to the temperature were calculated. Two replicate measurements for every sample were performed, and then the average value was taken as a result. After this, two main peaks in the derivative curve (DTG) were individuated and characterized by the following parameters: Peak temperature, height, and integral. For the first peak (peak 1) the quantification of the left and right (with respect to the peak temperature) integrals was also performed, whereas for peak 2 , an estimation of the temperature range, useful for the integral computation, was done. Peak temperatures and heights were determined by means of a regression curve (second or third-grade polynomial) in a strict range around the peak; integrals were determined as the total weight loss percentage between the considered temperature range limits; the temperature range was conventionally fixed in $25-200{ }^{\circ} \mathrm{C}$ for the first peak and determined for the second one from the intersections between the abscissa axis and the tangent passing for the inflection point of each (ascending and descending) part of the curve around the peak. 
Data were analyzed by means of statistical tools in order to assess the impact of the different parameters potentially affecting the process. With this regard, for each parameter, ANOVA tests and calculation of the Least Square Difference (LSD) were carried out according to [42]. The results of the statistical analysis are reported in Appendix B. The absolute values of the mean square differences were calculated comparing sample W50 with every sample of W, S, and Y group, while, regarding the influence of wheat variety, the reference value taken was the value CS1. These values were compared to the LSD calculated for each parameter to recognize which parameters are significantly different from the value taken as a reference.

Table 2. Composition of the samples here investigated.

\begin{tabular}{|c|c|c|c|c|c|}
\hline Sample & Water (\%) & Salt (\%) & Yeast (\%) & Semolina Variety & Mixing Time (min) \\
\hline W50 & 50 & 0 & 0 & CS & 20 \\
\hline W55 & 55 & 0 & 0 & $\mathrm{CS}$ & 20 \\
\hline W60 & 60 & 0 & 0 & CS & 20 \\
\hline S0.5 & 50 & 0.5 & 0 & $\mathrm{CS}$ & 20 \\
\hline S1.5 & 50 & 1.5 & 0 & CS & 20 \\
\hline $\mathrm{S} 3$ & 50 & 3 & 0 & CS & 20 \\
\hline Y0.5 & 50 & 0 & 0.5 & CS & 20 \\
\hline Y1.5 & 50 & 0 & 1.5 & CS & 20 \\
\hline $\mathrm{Y} 3$ & 50 & 0 & 3 & CS & 20 \\
\hline CS0.5 & 50 & 0 & 0 & CS & 2.5 \\
\hline CS1 & 50 & 0 & 0 & $\mathrm{CS}$ & 5 \\
\hline CS2 & 50 & 0 & 0 & CS & 10 \\
\hline A0.5 & 50 & 0 & 0 & A & 2 \\
\hline $\mathrm{A} 1$ & 50 & 0 & 0 & A & 4 \\
\hline $\mathrm{A} 2$ & 50 & 0 & 0 & A & 8 \\
\hline $\mathrm{C} 0.5$ & 50 & 0 & 0 & $\mathrm{C}$ & 1 \\
\hline $\mathrm{C} 1$ & 50 & 0 & 0 & C & 2 \\
\hline $\mathrm{C} 2$ & 50 & 0 & 0 & C & 4 \\
\hline
\end{tabular}

\section{Results}

\subsection{Effect of the Relative Amount of Ingredients}

The percentage weight reduction with respect to the initial weight of the sample, and its derivative, with respect to the temperature, as outputs of the TGA analysis, are shown for the $\mathrm{S}$ dough samples with different amounts of water (Figure 1), salt (Figure 2), and yeast (Figure 3). By observing the DTG curves in Figures 1-3, first, it can be noted that they present two main peaks: The first one (peak 1) is in the temperature range $105-130{ }^{\circ} \mathrm{C}$, the second one (peak 2) in the range $260-300{ }^{\circ} \mathrm{C}$. The peak 1 temperature and height values for samples with different amounts of water are shown in Figure 4, while the peak 2 height and temperature are shown in Figure 5. Figure 6 reports the integral values of the two peaks for the samples with different amounts of water. Regarding the yeast and salt impact, the parameters of the relative peaks are compared in the same graphs. The values for the peak 1 parameters are reported in Figure 7 (height and temperature) and Figure 8a (integral values). Figure 9 reports the height and temperature of peak 2 , and Figure $8 \mathrm{~b}$ shows its integral values.

Peak 1, that is observed just above $100{ }^{\circ} \mathrm{C}$, is supposed to be linked to water evaporation. Its occurrence is mainly due to the delivery of free water, but also to the starch gelatinization that begins at about $45{ }^{\circ} \mathrm{C}$, and finishes at about $85-90{ }^{\circ} \mathrm{C}$, when also the gluten reticulation is almost complete, as also reported in the literature [16]. As it can be observed in Figure $4 \mathrm{~b}$, for the W samples, the height of the first peak is higher as the water content increases. For the $S$ samples, the highest peak is for the S0.5 sample, and for S1.5 and S3.0, the height of the peak tends to decrease and stabilize (Figure $7 \mathrm{~b}$ ), while for the $\mathrm{Y}$ samples this parameter increases, reaching a maximum for the sample Y1.5, and then again decreases (Figure $7 \mathrm{~b}$ ). 


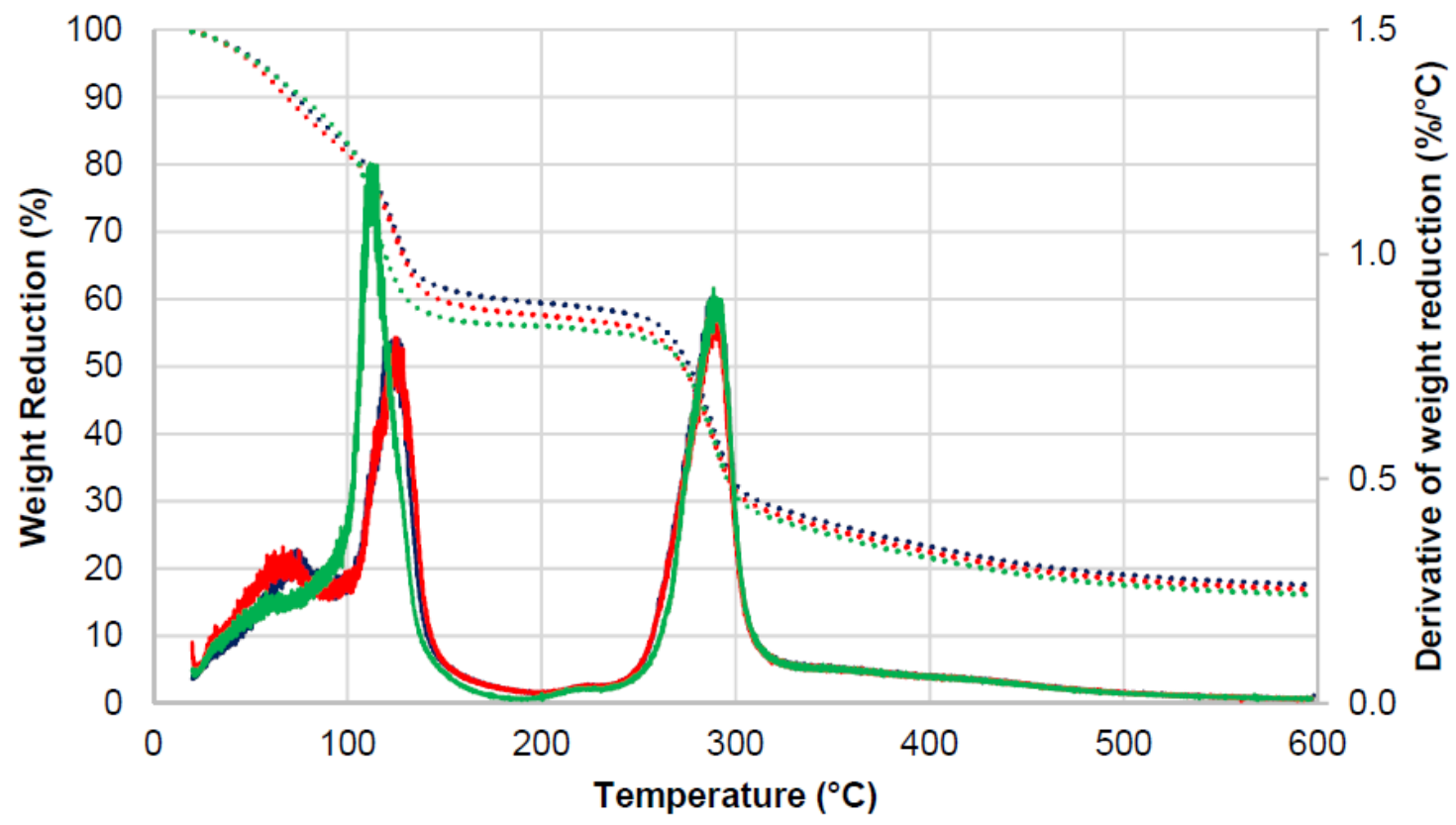

Figure 1. Weight reduction percentage (dashed lines) and derivative of weight reduction percentage with respect to the temperature (continuous lines) as a function of temperature for the semolina-water dough samples with a water amount of $50 \%(-), 55 \%(-)$, and $60 \%(-)$.

As it regards the temperature related to the peak 1, for the $\mathrm{W}$ samples, it decreases from about $123.8^{\circ} \mathrm{C}$ to about $112.2{ }^{\circ} \mathrm{C}$ when increasing the water amount from $50 \%$ to $60 \%$ (Figure $4 \mathrm{a}$ ), it decreases (from $123.8^{\circ} \mathrm{C}$ to $111.1^{\circ} \mathrm{C}$ ) also by varying the salt amount from $0 \%$ to $1.5 \%$, then slightly increases $\left(119.3^{\circ} \mathrm{C}\right.$ ) for the S3.0 sample (Figure 7a), and decreases again from $123.8^{\circ} \mathrm{C}$ to $107.3^{\circ} \mathrm{C}$ by varying the yeast amount from $0 \%$ to $1.5 \%$, then not significantly increases $\left(108.5^{\circ} \mathrm{C}\right)$ for the $\mathrm{Y} 3.0$ sample (Figure 7a).

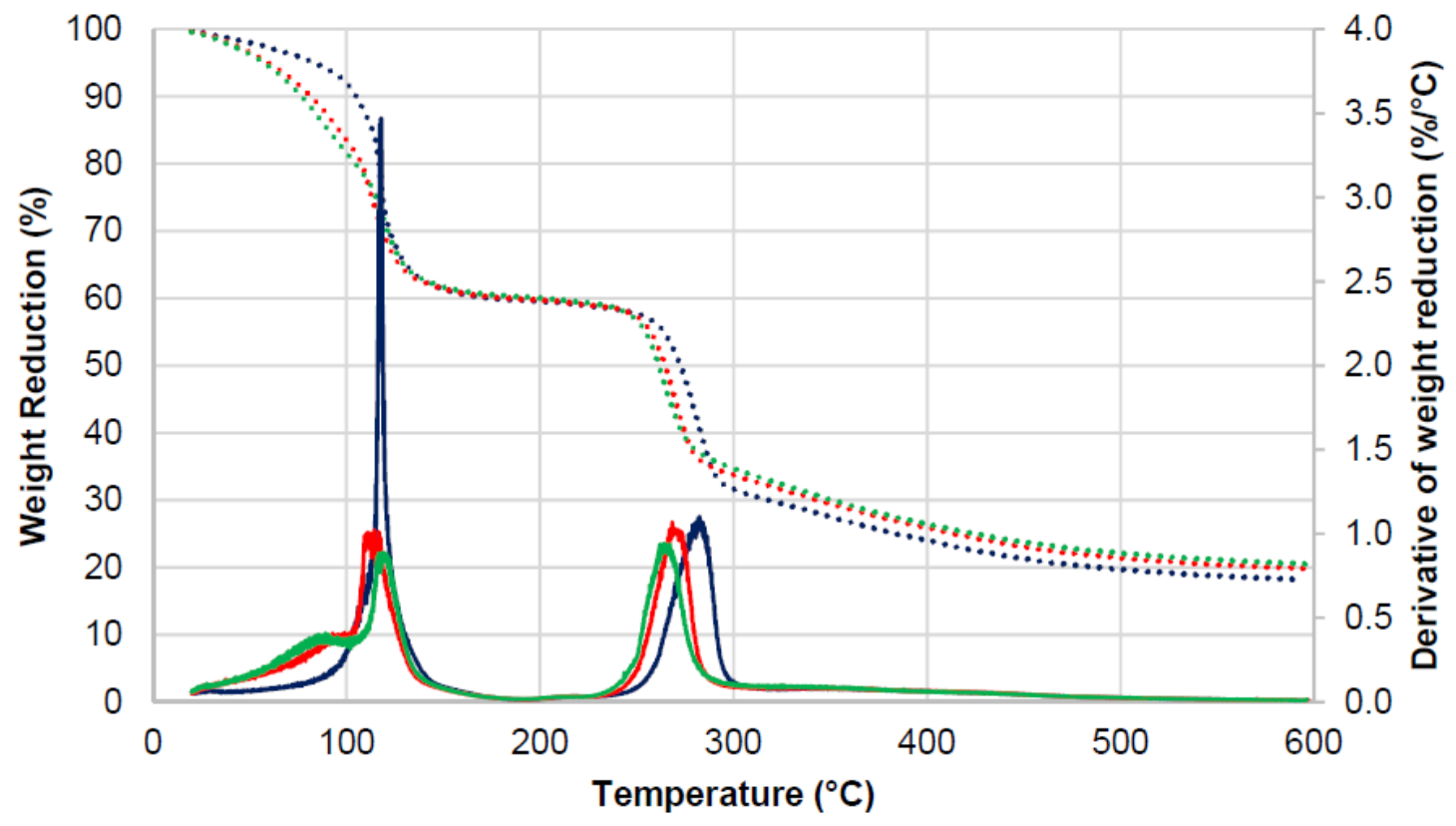

Figure 2. Weight reduction percentage (dashed lines) and derivative of weight reduction percentage with respect to the temperature (continuous lines) as a function of temperature for the semolina-water dough samples with a salt amount of $0.5 \%(-), 1.5 \%(-)$, and $3 \%(-)$. 
The peak 2 is assumed to be linked to the sample thermal destruction and in particular to the protein and gluten denaturation that occurs at about $292{ }^{\circ} \mathrm{C}$ [7]. For this peak, the differences in the peak temperature for the different amounts of ingredients are smaller than those observed for the peak 1 , because the process of sample destruction mainly depends on the protein content, which is not dependent on the amount of the other ingredients besides semolina. Despite this, analyzing the peak heights in Figures $5 \mathrm{~b}$ and $8 \mathrm{~b}$, it can be noted that the trend is similar to that of the peak 1 , except for the $\mathrm{W}$ samples, in which there is a slight minimum for the W55 sample (Figure $5 b$ ). In addition, it is possible to note (Figure $9 \mathrm{a}$ ) that the peak 2 temperature for the $S$ samples significantly decreases as the salt amount increases. This phenomenon could be related to the salt influence on the protein process hydration, which leads to a weaker protein structure [19].

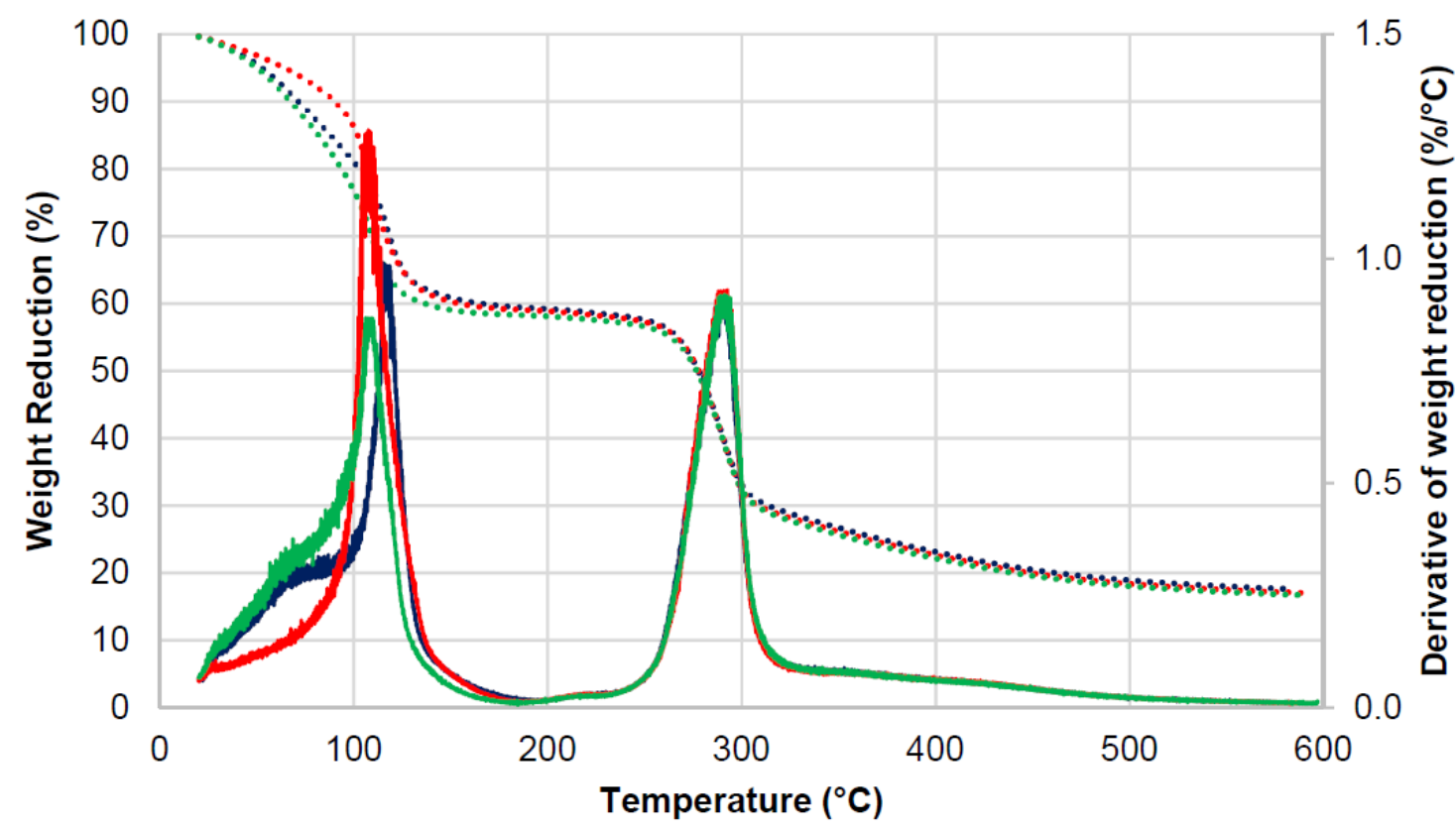

Figure 3. Weight reduction percentage (dashed lines) and derivative of weight reduction percentage with respect to the temperature (continuous lines) as a function of temperature for the semolina-water dough samples with a yeast amount of $0.5 \%(-), 1.5 \%(-)$, and $3 \%(-)$.

The peak 1 integral values, reported in Figures 6 and 9a, tend to decrease when water (Figure 6) and salt (Figure 8a) amounts increase, while they increase with an increase in the yeast amount (Figure 8a). On the other hand, the peak 2 integral values (Figures 6 and 9b) slightly decrease in every case.

The above results allow conjecturing optimal process conditions. In this regard, the following main aspects should be noted. The amount of water should be maintained between 50 and $55 \%$, as higher amounts negatively impact the dough structure building: Peak 1 appears at lower temperatures and its height increases, which means that too much free water is present. The amount of yeast, for the same reasons, should be minimized, but the optimum value should be more carefully investigated, also taking into account the leavening time, which is also expected to produce effects on the final product properties. Additionally, the amount of salt should be minimized, mainly due to its negative effect on the strength of the protein structure, as can be seen from the behavior of peak 2 temperature and integral, but it should be more deeply investigated with respect to the impact on the organoleptic properties of the final product. 


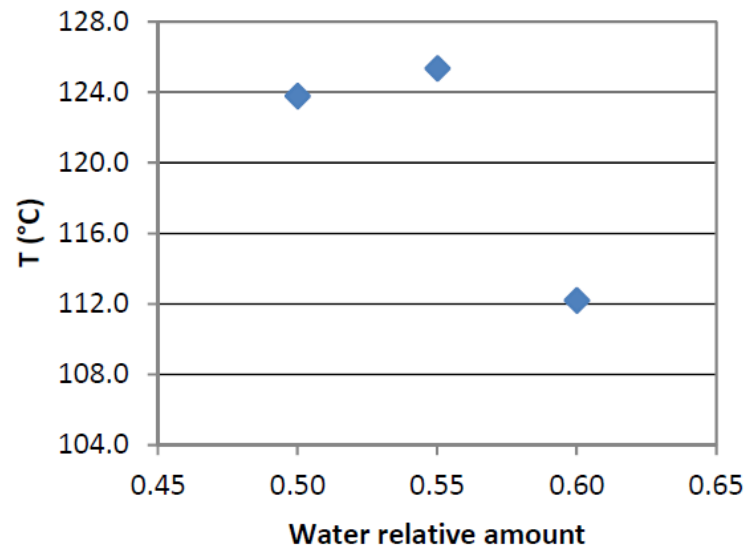

(a)

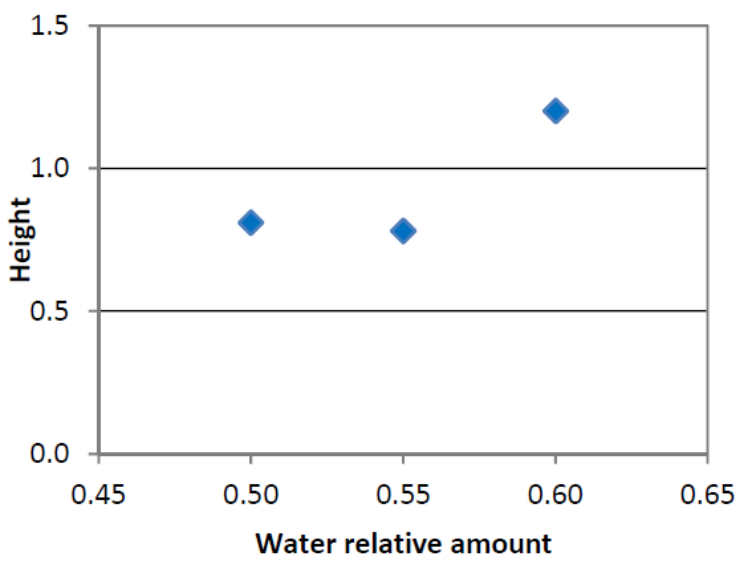

(b)

Figure 4. Peak 1 temperature (a) and height (b) as a function of the water relative amount.

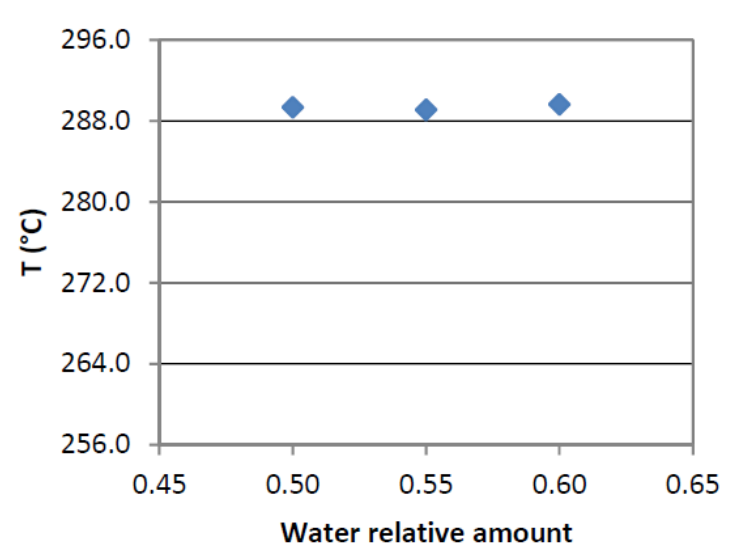

(a)

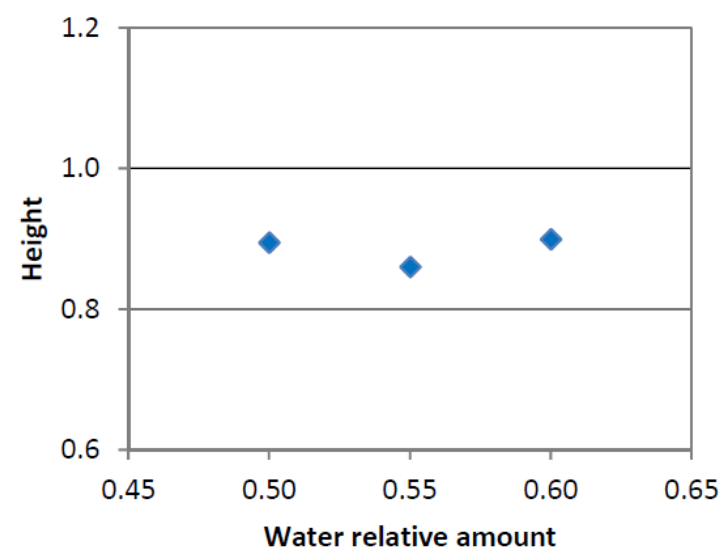

(b)

Figure 5. Peak 2 temperature (a) and height (b) as a function of the water relative amount.

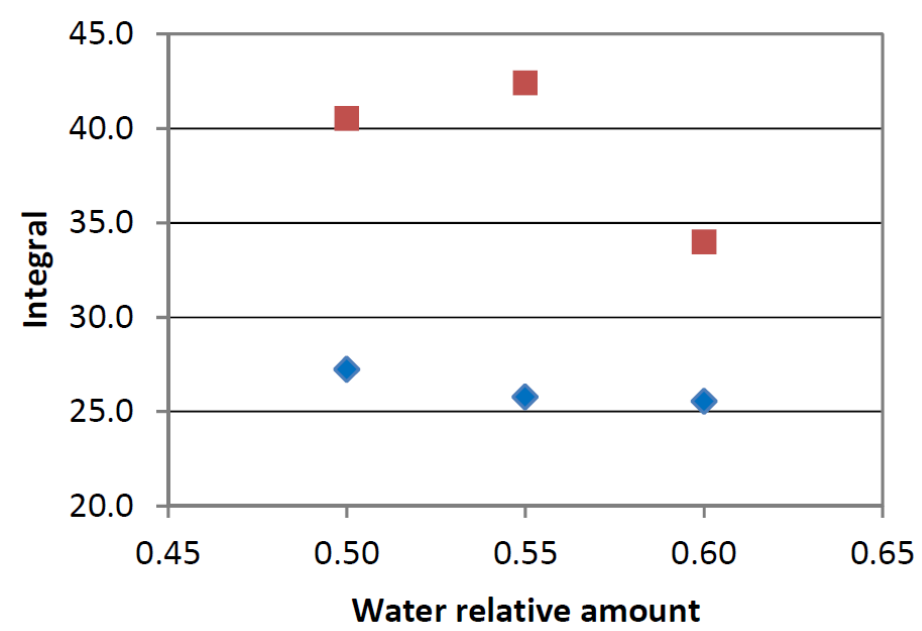

Figure 6. Total values of integrals of the peak 1 (red squares) and peak 2 (blue diamonds) as a function of the water relative amount. 


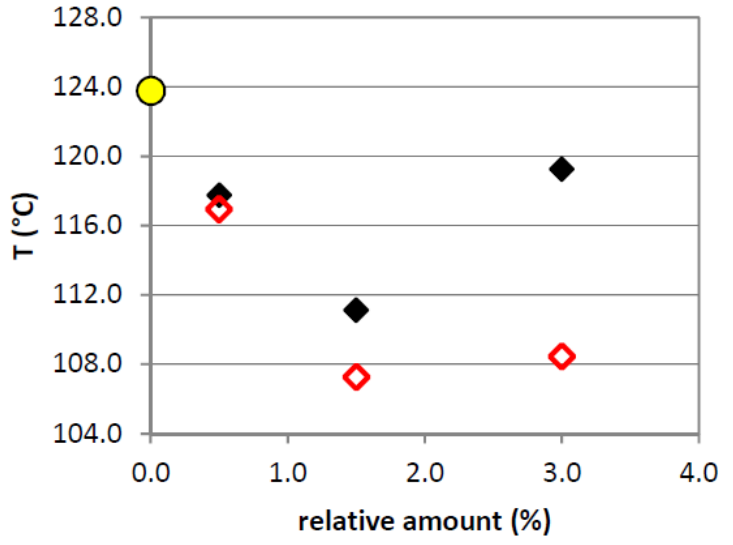

(a)

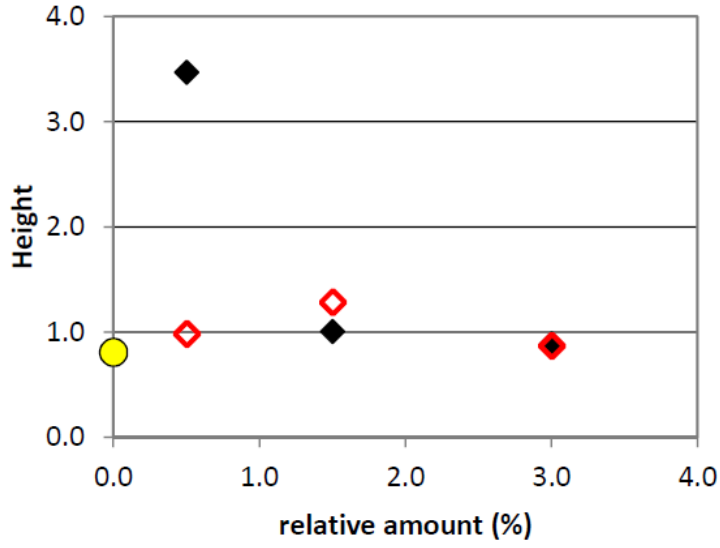

(b)

Figure 7. Peak 1 temperature (a) and height (b) as a function of salt (black diamonds) and yeast (red diamonds) relative amount. The yellow point represents the control sample.

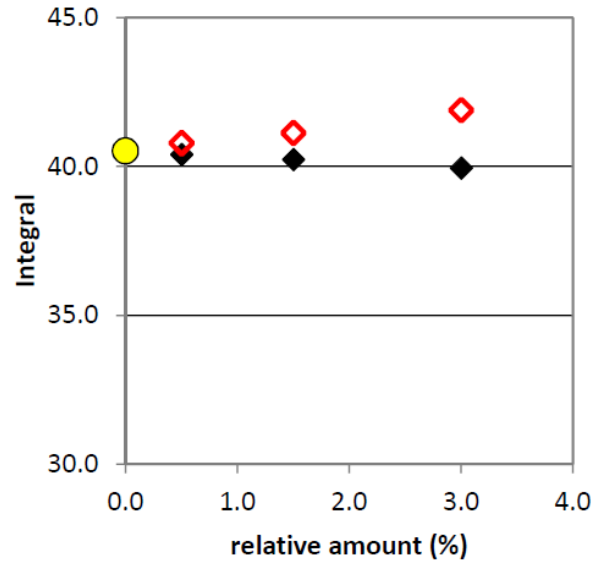

(a)

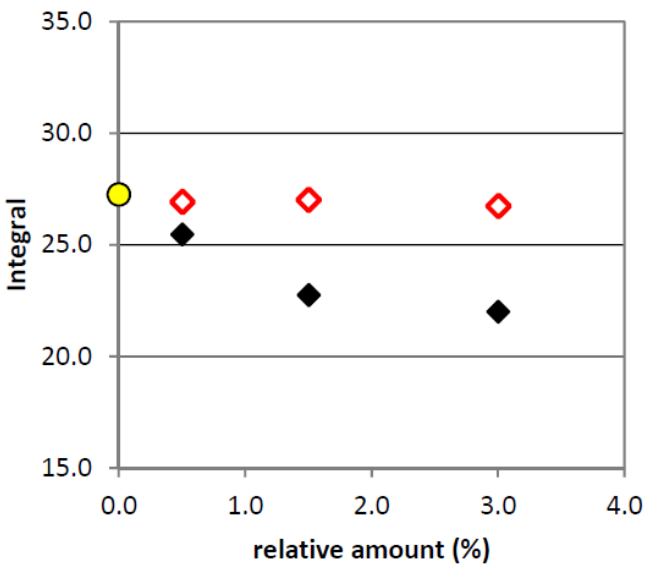

(b)

Figure 8. Peak 1 (a) and peak 2 (b) integral as a function of salt (black diamonds) and yeast (red diamonds) relative amount. The yellow point represents the control sample.

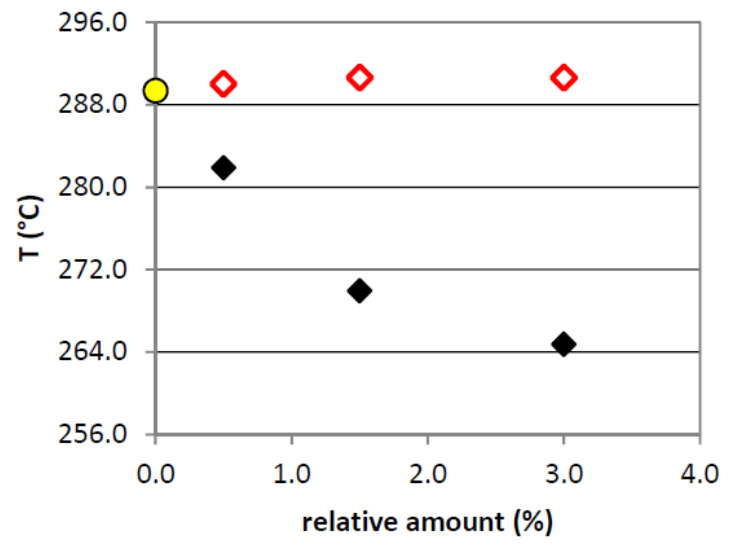

(a)

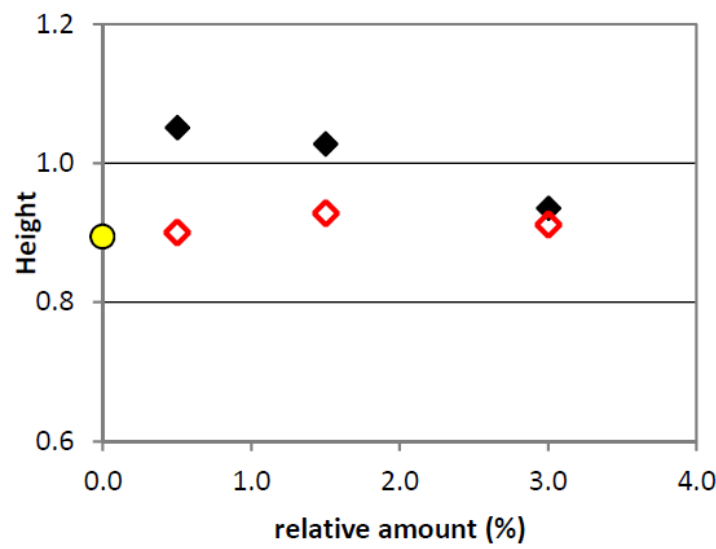

(b)

Figure 9. Peak 2 temperature (a) and height (b) as a function of salt (black diamonds) and yeast (red diamonds) relative amount. Yellow point represents the control sample. 


\subsection{Effect of Wheat Variety and Mixing Time}

The results of TGA, i.e., the weight reduction calculated as the percentage reduction with respect to the initial weight of the sample, and its derivative with respect to the temperature, are shown for CS semolina dough (Figure 10) with $50 \%$ of water and no yeast or salt, for the three different kneading times considered ( $\mathrm{A}$ and $\mathrm{C}$ semolina dough weight reduction and derivative, as a function of mixing time, are reported in Figures A1 and A2, respectively, in the appendix section). Furthermore, the comparison between the height and the peak temperature of the peaks 1 and 2 for the three semolina varieties are reported, respectively, on Figures 11 and 12 as a function of the kneading time. Finally, Figure 13 contains the comparison of the different semolina results for the different kneading times regarding the integral values of the peaks 1 and 2 .

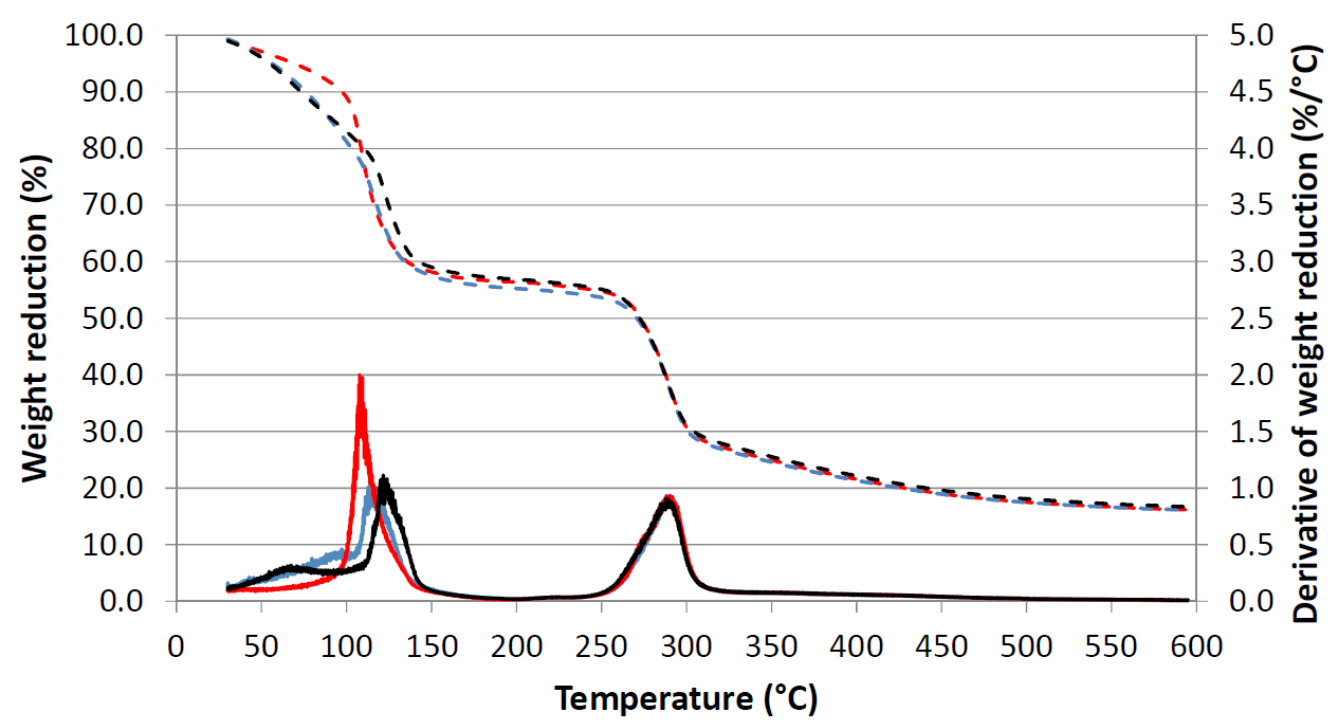

Figure 10. Weight reduction percentage (dashed lines) and derivative of weight reduction percentage with respect to the temperature (continuous lines) as a function of temperature for CS dough samples kneaded for $2.5 \mathrm{~min}(-), 5 \mathrm{~min}(-)$, and $10 \min (-)$.

By observing the DTG curves (Figure 10, and also Figures A1 and A2), also in this case, it can be noted that they present two main peaks: The peak 1 occurring in the temperature range $105-120^{\circ} \mathrm{C}$ and the peak 2 in the range $280-300{ }^{\circ} \mathrm{C}$. Moreover, looking at the weight reduction curves (Figures 10, A1 and A2), it can be observed that the first reduction, between 50 and $120^{\circ} \mathrm{C}$, is faster for the samples which were obtained at the optimum kneading time and the slope of the curve results higher for these samples.

For $\mathrm{S}$ and $\mathrm{A}$ semolina dough, the peak 1 temperature increases as the kneading time increases, varying from 108.0 to $122.0^{\circ} \mathrm{C}$ for $\mathrm{CS}$ and from 106.2 to $110.3^{\circ} \mathrm{C}$ for A (Figure 11a). In the case of the C dough, instead, the maximum peak temperature $\left(110.0^{\circ} \mathrm{C}\right)$ showed for the optimum kneading time, and the minimum value $\left(105.2^{\circ} \mathrm{C}\right)$ is still that of the undeveloped dough (Figure 11a).

Regarding peak 2 , the differences in the peak temperature for the different mixing times are smaller than those of the peak 1 . However, the peak temperature tends to decrease as the kneading time increases (Figure 12a). A dough presents the highest peak 2 temperatures, thus it is possible to conclude that is able to build the strongest protein structures.

Analyzing the data of peak heights, it can be noted that the samples kneaded till the optimum time showed the lower height of the peak 1 (Figure 11b), whilst the under-mixed sample presents a very higher peak height value if compared with the other two samples related to A and CS semolina doughs. CS dough, on the contrary, presents the lowest value of peak 1 height when it is under-mixed. This phenomenon can be related to the higher presence of free water in the undeveloped dough, since also the peak temperature is slightly higher than the water normal boiling point. Regarding the second 
peak height values, reported in Figure 12b, these are much more stable with the mixing time, because the total protein content is not dependent on the kneading process.

Additionally, the value of weight reduction at $600.0^{\circ} \mathrm{C}$ (readable in Figures 10, A1 and A2), is more stable, and so less indicative, as the mixing time was varied.

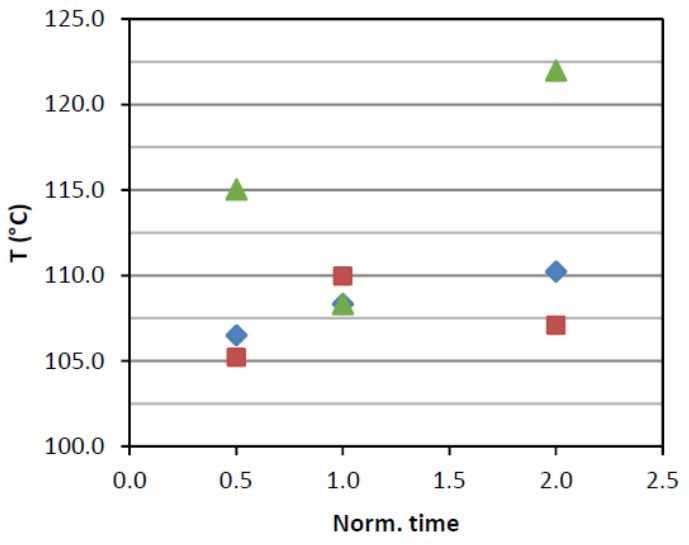

(a)

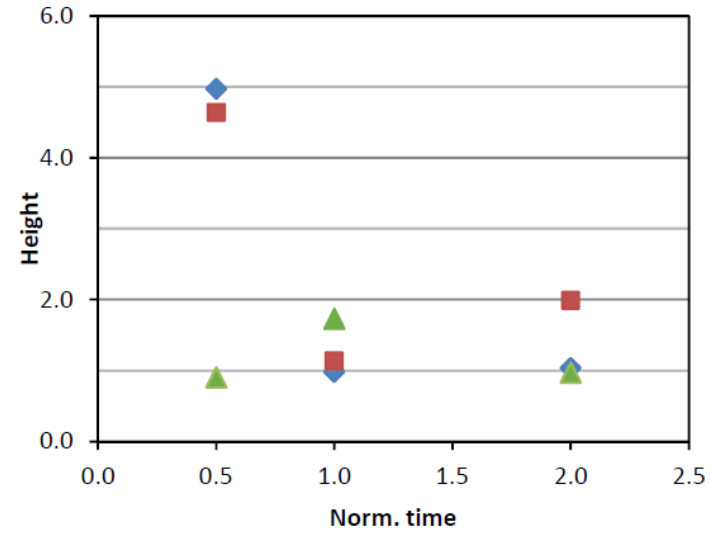

(b)

Figure 11. Peak 1 temperature (a) and height (b) as a function of the normalized kneading time for the A $(\diamond), C(\square)$, and CS $(\Delta)$ semolina dough.

The peak integral values, reported in Figure 13, tend to decrease with the mixing time increasing for the peak 1 (Figure 13a); the peak 2 integral values, instead, present a minimum for the well-developed dough $\mathrm{A}$ and $\mathrm{C}$, and a maximum for CS at the optimal mixing time (Figure 13b).

The peak 2 heights are higher for $C$ semolina samples, and this phenomenon is probably linked to the lower strength of the gluten network of these doughs, which also presents a faster weight reduction. The weight reduction at $600.0^{\circ} \mathrm{C}$ is higher for $\mathrm{A}$ semolina doughs due to its higher protein content. Regarding the integral values for peak 1 , CS semolina samples show a higher value of the integral, which can be caused by the presence of more bonded water. For the peak 2 integral, instead, the CS semolina samples showed the lowest value, this is probably due to the presence of fewer impurities in this semolina, which is better sifted compared to the other two semolina samples; furthermore, A and $\mathrm{C}$ grains were milled in an artisanal way, which improves the content of impurities. Typical impurities in the flour are part of weed seeds or grain, extraneous matter (like dust, sand or soil particles), husks, ergot, and fragments of insects.

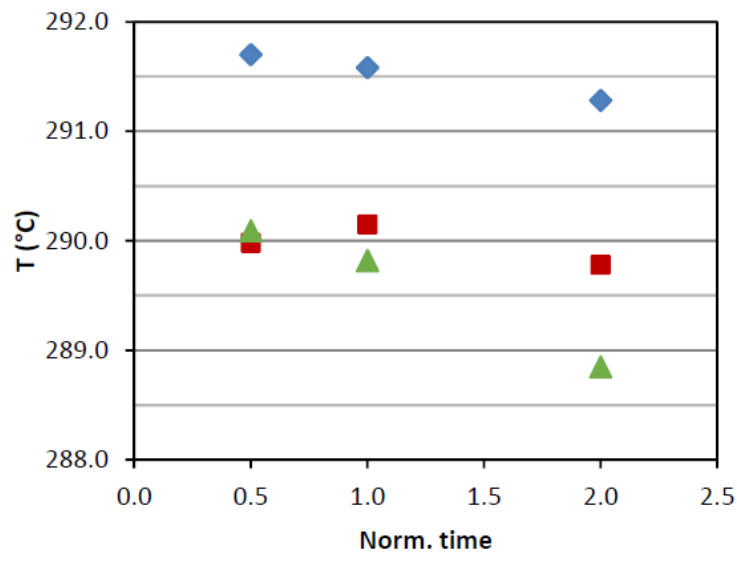

(a)

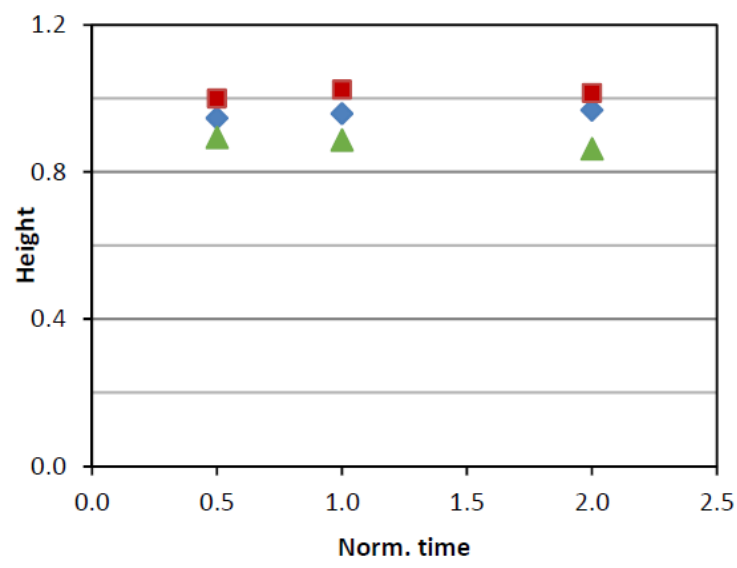

(b)

Figure 12. Peak 2 temperature (a) and height (b) as a function of the normalized kneading time for the A $(\diamond), C(\square)$, and CS $(\Delta)$ semolina dough. 


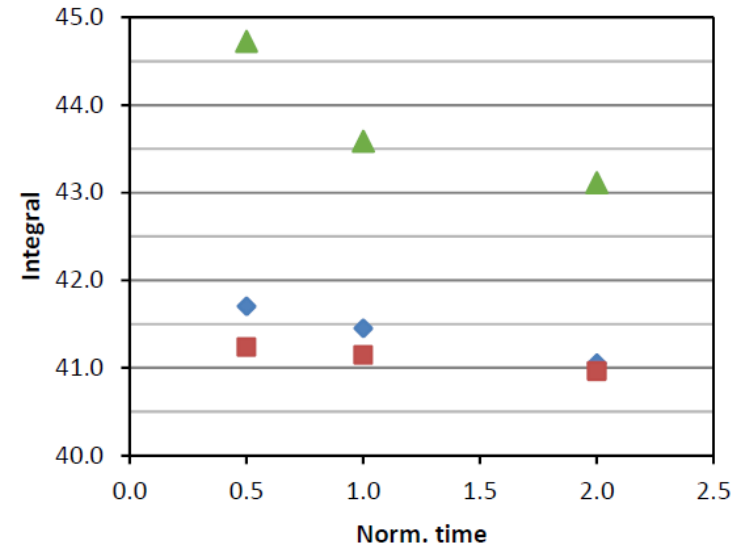

(a)

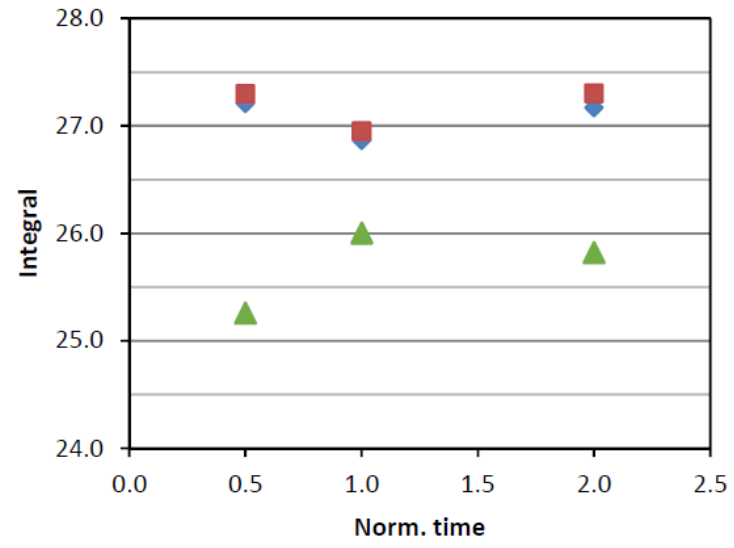

(b)

Figure 13. Peak 1 (a) and peak 2 (b) integral values reported as a function of the normalized kneading time for the A $(\triangleleft), C(\square)$, and CS (^) semolina dough.

\subsection{Rheological Properties}

The rheological properties of the CS dough under study were already examined in a previous work by Fanari et al. [2]. These results were compared to those already obtained for the A and C semolina [38]. In both works, complex moduli data were modeled as a function of the deformation frequency by means of the weak gel model [43] reported in Equation (1):

$$
G^{*}(\omega)=\sqrt{G^{\prime}(\omega)^{2}+G^{\prime \prime}(\omega)^{2}}=A_{F} \omega^{\frac{1}{z}}
$$

where $G^{*}$ is the complex viscoelastic modulus, $\omega$ is the frequency, $A_{F}$ is a model parameter that is related to the strength of the interactions among the flow units (i.e., the strength of the network structure), and $z$ is a model parameter, which is linked to the extension of the three-dimensional network. In the literature, there are several examples of weak gel model applications to the characterization of doughs $[2,38,44-46]$.

The rheological data obtained by Fanari et al. $[2,38]$ were compared with the results of the present work. In particular, the values of integral 1 and integral 2 were compared to the weak gel model parameter values obtained with doughs carried out at the very same conditions. The interest was mainly focused on the peak 1 and 2 integral values since they showed the most significant differences among the samples prepared with the three typologies of semolina (see, e.g., Tables A6 and A12) and for this reason, they were considered as the most representative parameters. Figure 14 reports the comparison between the $A_{F}$ parameter and the thermal parameters peak 1 and peak 2 integrals (Figure 14a,b, respectively). Figure 15 shows the analogies of the rheological z parameter with peak 1 integral (Figure 15a) and peak 2 integral (Figure 15b). The G.I. parameter, often used as a measure of the strength of the gluten structure, was taken as a comparison parameter.

Moreover, in Figures 16 and 17, the rheological and thermal parameters are directly related, considering the values of the two replicate measurements carried out for each sample. The statistical correlation coefficient ( $r$ ) and the p-value for each couple of parameters compared were calculated to investigate if the correlation is statistically significant. In particular, it was found that peak 1 integral is directly correlated with $\mathrm{A}_{\mathrm{F}}(r=0.977)$ and $\mathrm{z}(r=0.948)$, while peak 2 integral is inversely proportional to $\mathrm{A}_{\mathrm{F}}(r=-0.864)$ and $\mathrm{z}(r=-0.829)$. The correlation is statistically significant, regarding $\mathrm{A}_{\mathrm{F}}$ and peak 1 integral $(p-$ value $=7.62 E-04)$, but also $\mathrm{z}$ and peak 1 integral $(p-$ value $=3.92 E-03)$; regarding the peak 2 integral, the $\mathrm{p}$ values are slightly higher but still lower than $0.5 \%\left(\mathrm{~A}_{\mathrm{F}} \mathrm{vs}\right.$ peak 2 temperature, $p-$ value $=2.62 E-02 ; \mathrm{z}$ vs. peak 2 temperature, $p-$ value $=4.14 E-02)$, so it is still possible to state that there is a significant correlation. 


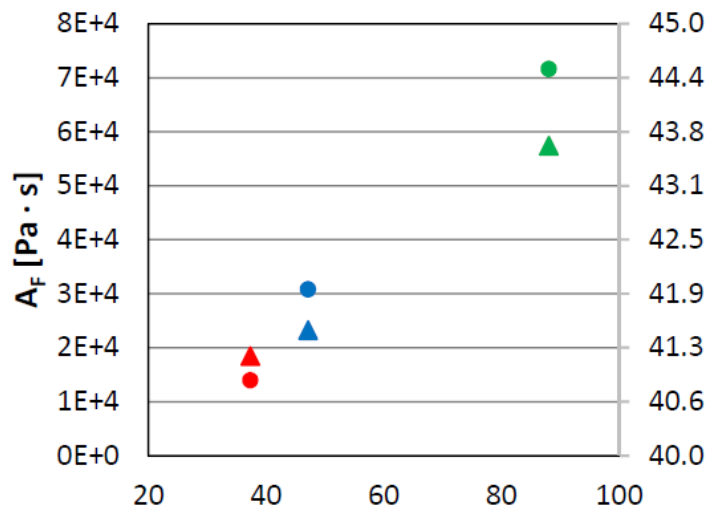

G. I. [\%]

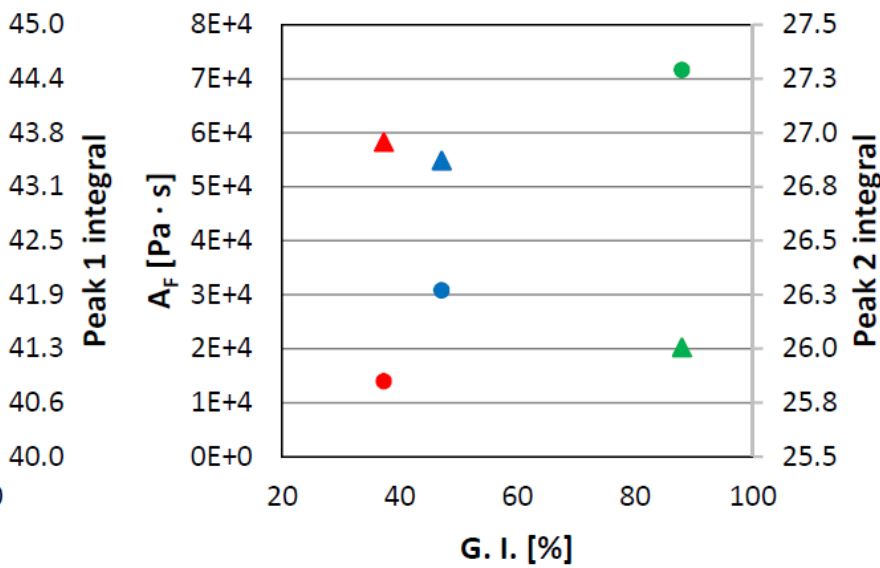

(b)

Figure 14. $A_{F}$ parameter (points) compared with the value of peak 1 integral (triangles) (a) and of peak 2 integral (triangles) (b) as a function of the semolina G.I. for the dough samples A $(\bullet), C(\bullet)$, and CS (•).

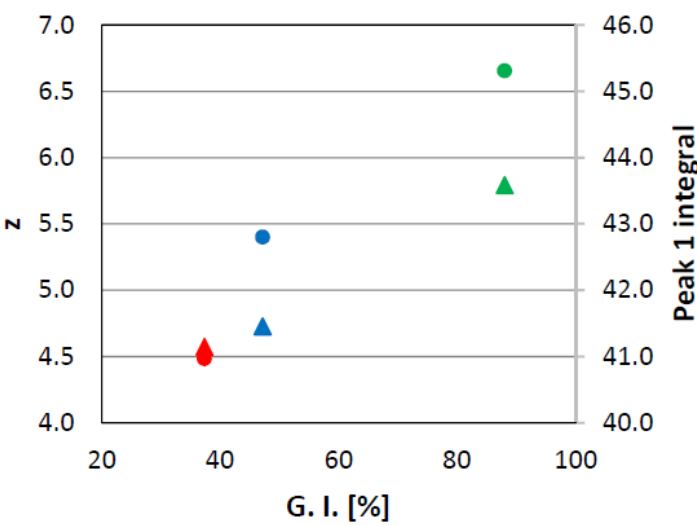

(a)

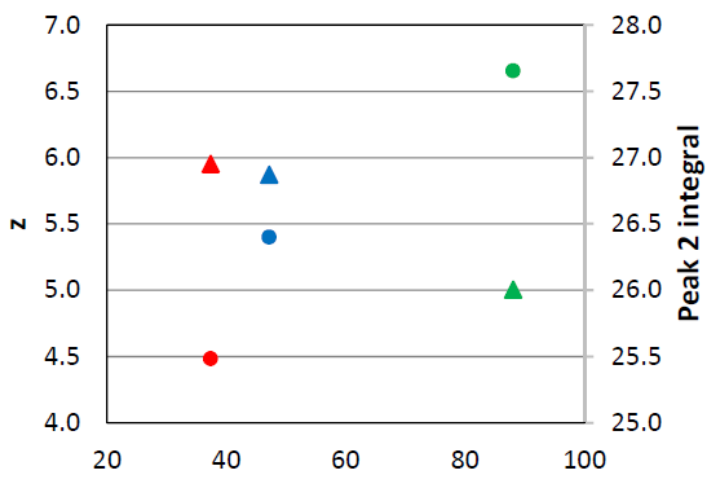

G. I. [\%]

(b)

Figure 15. z parameter (points) compared with the value of peak 1 integral (triangles) (a) and of peak 2 integral (triangles) (b) as a function of the semolina G.I. for the dough samples A $(\bullet), C(\bullet)$, and CS (•).

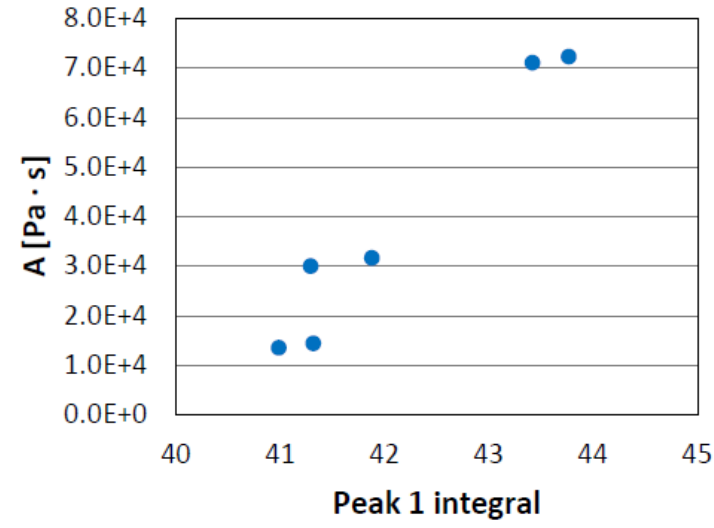

(a)

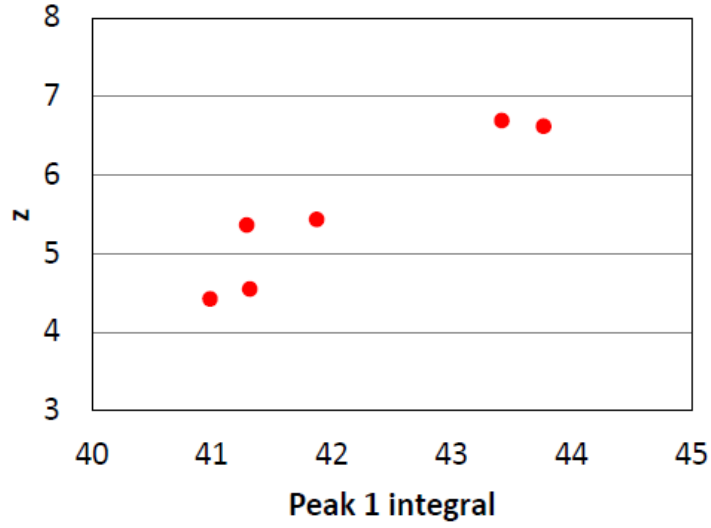

(b)

Figure 16. AF parameter (a) and $\mathrm{z}$ parameter $(\mathbf{b})$ for the three semolina samples considered, as a function of peak 1 integral. 


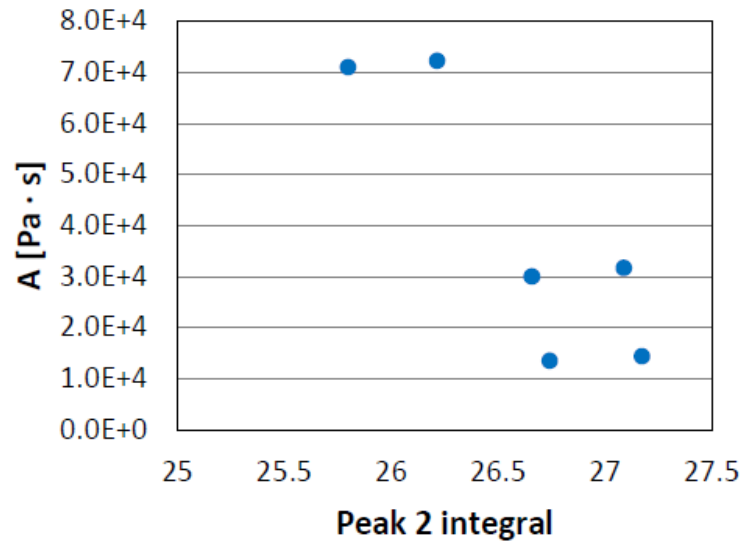

(a)

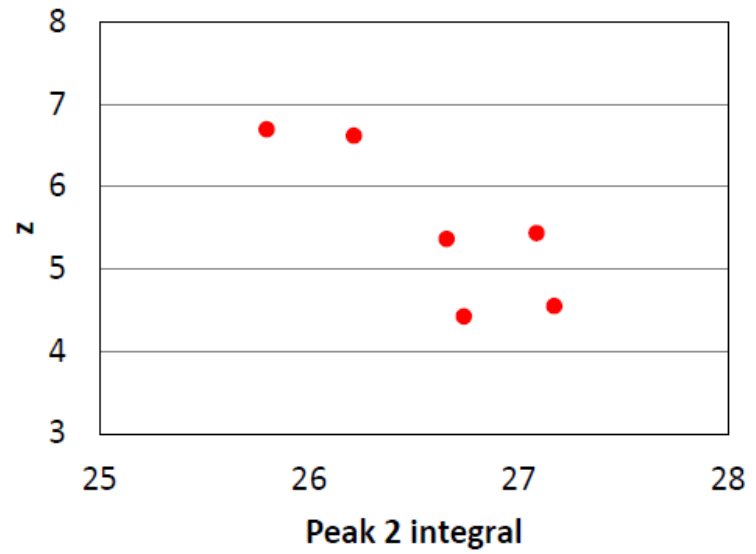

(b)

Figure 17. $A_{F}$ parameter (a) and $z$ parameter $(\mathbf{b})$ for the three semolina samples considered, as a function of peak 2 integral.

\section{Discussion}

Some remarks concerning the previous results are in order. The results presented were related to the statistical analysis reported in Appendix B The ANOVA tests carried out on the different thermal parameters (Tables A1, A3, A5, A7, A9 and A11) together with the absolute mean square deviation values estimated by comparing different ingredient concentrations. As expected, there is a significant impact of the treatments on the parameters, as confirmed by the small p-values obtained.

First, one should notice that, as it regards the peak 1 temperature, it is possible to state that this parameter is affected by water (especially when its concentration is higher than $55 \%$ ), salt, yeast, and to a lesser extent, by the mixing time, as it can be appreciated from Table A2. In particular, mixing time influences peak 1 temperature only at high gluten content and gluten index (this feature is more evident for the CS semolina), probably because the higher quantity of gluten proteins results in a longer hydration time. On the other hand, peak 1 height is influenced by the semolina variety and mixing time with absolute mean square difference values higher than LSD (Table A4). As it regards peak 1 integral, the significant differences are reported changing the semolina variety and yeast, adding salt in high quantities more (at least 3\%) and still adding water (Table A6). As a general statement, we can confirm that this peak is mainly influenced by water availability.

About peak 2 temperature, the salt results to be the only parameter significantly affecting the thermal properties (Table A8). The same conclusion can be drawn on for peak 2 height, but in this case, also the different semolina variety plays a role (Table A10). Moreover, the parameters that affect the peak 2 integral are water, salt, and semolina variety (Table A12).

Furthermore, a comparison of the results concerning the thermal and the rheological properties leads to some interesting considerations. First, as it regards the comparison between the different semolina varieties, the semolina with the strongest and most extended network (CS) presents also the highest peak 1 integral. In particular, the differences in the peak 1 integral value among the varieties are very analogous to the ones shown by the weak gel model parameters. As previously reported, the trends of the thermal and rheological parameters with respect to G.I. are very similar. In one case, the trend is the same, in more detail, the peak 1 integral and weak gel parameters together increase with the gluten index. On the other hand, the peak 2 integral decreases with the gluten index, whereas 
the rheological parameters behave in the opposite sense. So, it is possible to say that peak 1 integral is directly related to G.I., strength, and extension of the network. As it regards the peak 2 integral, its value is inversely related to G.I., force, and extension of the gluten network.

\section{Conclusions}

The TGA, conducted on semolina doughs revealed to be an interesting tool capable of showing the differences in the dough characteristics, mainly due to the different composition and availability of water, which change during the development of the gluten molecular network and are revealed by the peak 1 . The peak 2 shows differences linked to impurities and bond strength of the structure. As it regards the ingredients, the free water availability turned out to be one of the most important properties affecting the dough structure building (starch gelatinization and gluten network formation), so it is important to control its amount. Additionally, the yeast and salt amount were revealed to be critical, but their role is less clear and appreciable, at least if compared to the water effect. This aspect needs to be evaluated together with the leavening process (not addressed in this work).

Moreover, the mixing (kneading) role mainly affects the peak 1 shape and position, as both the free water availability and the dough network building (starch gelatinization and gluten reticulation) status are changing during the kneading process. In particular, when the mixing time increases, the peak temperature increases and the height decreases, since the free water availability is decreasing.

Regarding peak 1, comparing the different semolina varieties under study, it is possible to observe that $\mathrm{S}$ semolina doughs present the lowest but broadest peak. This suggests that water is strongly bounded, and there is less free water if compared to the other two semolina. This feature seems to be likely due to the higher value of total proteins in the CS semolina. This results also in a stronger and more extended network structure.

On the other hand, the gluten content and index mainly showed their influence on the integral values of peak 1 and peak 2 , for which the highest differences were found depending on the semolina variety, while the contribution of the kneading time, even if detected, is almost negligible when compared to the previous one. This feature is corroborated by the outcomes provided by the rheological experiments on the samples. Indeed, when G.I. increases, the gluten structure properties improved, and peak 1 integral increases with a similar trend at the same time, whereas peak 2 integral decreases showing an inverse trend.

The information here obtained meets the need of improving the sustainability of industrial bread productions, particularly those realized at a small-medium scale, where large amounts of products are lost because of off-specification, due to the very high lag times (most of the defects are realized only after baking). Thus, for this kind of process, the introduction of new monitoring and control techniques, based on measurable parameters, could bring a reduction in the material losses, which would produce a direct improvement in the energy efficiency of the process.

Author Contributions: Conceptualization, F.D., and F.F.; methodology, F.D.; software, F.F.; validation, M.G., and F.D.; investigation, F.F.; resources, F.D. and G.C.; data curation, F.F., and F.D.; writing — original draft preparation, F.F.; writing - review and editing, F.D. and M.G.; supervision, F.D. and M.G.; project administration, F.D.; funding acquisition, F.D. All authors have read and agreed to the published version of the manuscript.

Funding: This research was funded by Regione Autonoma della Sardegna, POR FESR Sardegna 2014-2020, Programma di ricerca e sviluppo "Agroindustria" (Determinazione del D.G. di Sardegna Ricerche DG 578 RIC del 10/04/2018).

Conflicts of Interest: The authors declare no conflict of interest. The funders had no role in the design of the study; in the collection, analyses, or interpretation of data; in the writing of the manuscript, or in the decision to publish the results. 


\section{Appendix A}

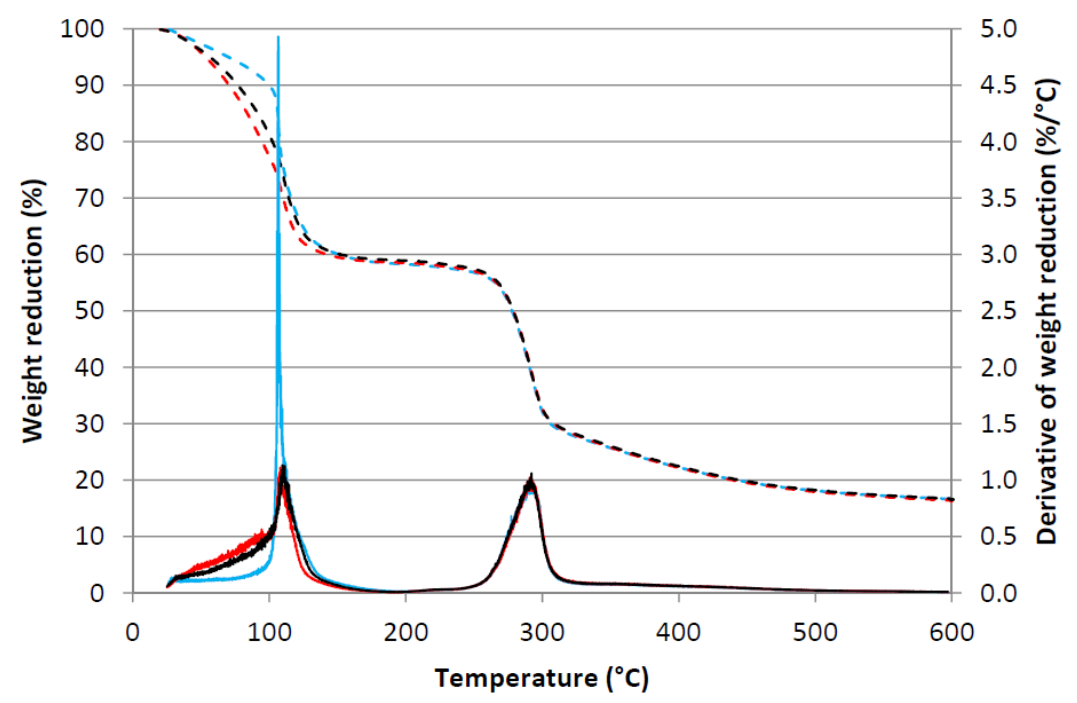

Figure A1. Weight reduction percentage (dashed lines) and derivative of weight reduction percentage with respect to the temperature (continuous lines) as a function of temperature for Alemanno semolina dough samples kneaded for $2 \min (-), 4 \min (-)$, and $8 \min (-)$.

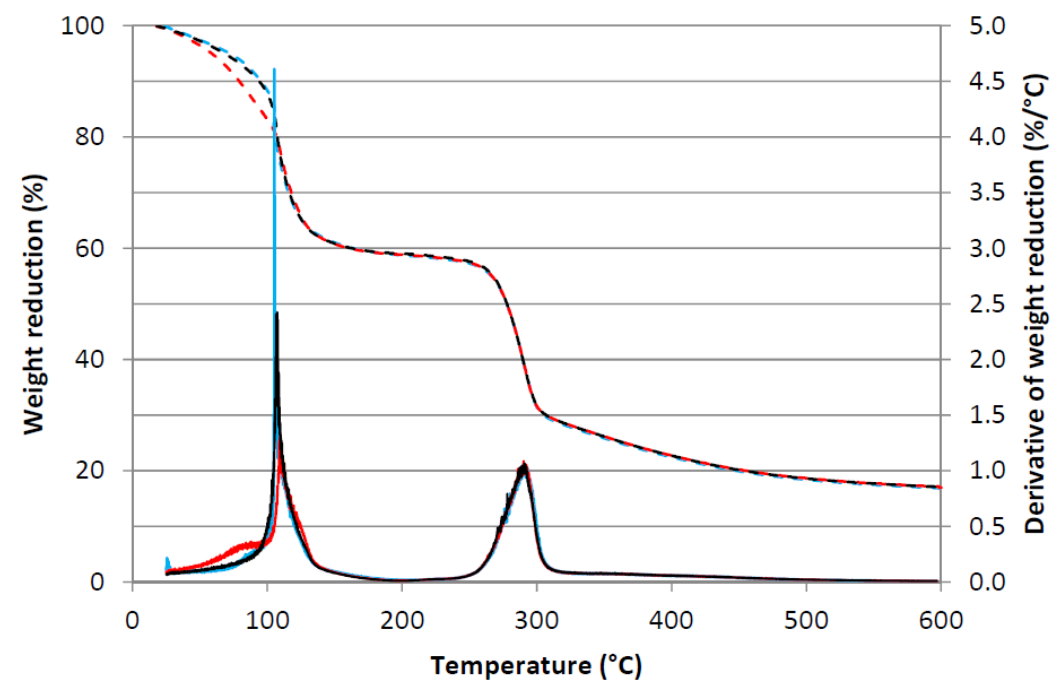

Figure A2. Weight reduction percentage (dashed lines) and derivative of weight reduction percentage with respect to the temperature (continuous lines) as a function of temperature for Cappelli semolina dough samples kneaded for $2 \mathrm{~min}(-), 4 \mathrm{~min}(-)$, and $8 \mathrm{~min}(-)$.

\section{Appendix B}

ANOVA tests were carried out on the different thermal parameters here estimated, in order to assess the impact of the different formulations. This has led to the setting of 18 different treatments, represented by the different samples (reported in Tables A2, A4, A6, A8, A10, and A12, each table for a different parameter), and for each one of them, two replicates have been made available.

In the following, the ANOVA table for each parameter is reported (Tables A1, A3, A5, A7, A9 and A11) together with the absolute mean square deviation values estimated by comparing different ingredient concentrations. For the sake of completeness, the Least Square Deviation (LSD) computed for each dataset is also reported in the MSD table. The combinations leading to an MSD higher than the LSD are classified as significant and they are highlighted in bold. The same notation will be used thoroughly in Appendix B. 
Table A1. ANOVA test results for peak 1 temperature.

\begin{tabular}{ccccccc}
\hline Source of Variation & SS & DoF & MS & F & $p$-Value & F Crit \\
\hline Samples & 1373.451 & 17 & 80.791 & 31.506 & $5.47 \mathrm{E}-10$ & 2.232 \\
Error & 46.158 & 18 & 2.564 & & & \\
Total & 1419.609 & 35 & & & & \\
\hline
\end{tabular}

Table A2. The absolute value of MSD for the parameter peak 1 temperature, for the treatments investigated with the ANOVA test. For the sake of comparison, the LSD value is also reported in the table.

\begin{tabular}{cc}
\hline Samples under Comparison & MSD Absolute Value \\
\hline W50-W55 & 1.570 \\
W50-W60 & $\mathbf{1 1 . 5 8 0}$ \\
W50-S0.5 & $\mathbf{6 . 0 2 0}$ \\
W50-S1.5 & $\mathbf{1 2 . 6 5 0}$ \\
W50-S3 & $\mathbf{4 . 5 0 0}$ \\
W50-Y0.5 & $\mathbf{6 . 8 3 0}$ \\
W50-Y1.5 & $\mathbf{1 6 . 5 2 0}$ \\
W50-Y3 & $\mathbf{1 5 . 3 2 0}$ \\
CS1-CS0.5 & $\mathbf{6 . 7 2 0}$ \\
CS1-CS2 & $\mathbf{1 3 . 6 7 0}$ \\
CS1-A1 & 0.020 \\
CS1-C1 & 1.660 \\
A1-A0.5 & 1.840 \\
A1-A2 & 1.890 \\
C1-C0.5 & $\mathbf{4 . 7 7 0}$ \\
C1-C2 & 2.880 \\
\hline LSD & 3.364 \\
\hline
\end{tabular}

Table A3. ANOVA test results for peak 1 height.

\begin{tabular}{ccccccc}
\hline Source of Variation & SS & DoF & MS & F & $p$-Value & F Crit \\
\hline Samples & 58.803 & 17 & 3.459 & 80.990 & $1.53 \mathrm{E}-13$ & 2.232 \\
Error & 0.769 & 18 & 0.043 & & & \\
Total & 59.572 & 35 & & & & \\
\hline
\end{tabular}

Table A4. The absolute value of MSD for the parameter peak 1 height, for the treatments investigated with the ANOVA test. For the sake of comparison, the LSD value is also reported in the table.

\begin{tabular}{cc}
\hline Samples under Comparison & MSD Absolute Value \\
\hline W50-W55 & 0.029 \\
W50-W60 & 0.392 \\
W50-S0.5 & $\mathbf{2 . 6 6 1}$ \\
W50-S1.5 & 0.197 \\
W50-S3 & 0.078 \\
W50-Y0.5 & 0.176 \\
W50-Y1.5 & $\mathbf{0 . 4 7 5}$ \\
W50-Y3 & 0.062 \\
CS1-CS0.5 & $\mathbf{0 . 8 2 0}$ \\
CS1-CS2 & $\mathbf{0 . 7 5 2}$ \\
CS1-A1 & $\mathbf{0 . 7 4 4}$ \\
CS1-C1 & $\mathbf{0 . 5 8 4}$ \\
A1-A0.5 & $\mathbf{3 . 9 9 7}$ \\
A1-A2 & 0.060 \\
C1-C0.5 & $\mathbf{3 . 4 9 9}$ \\
C1-C2 & $\mathbf{0 . 8 5 1}$ \\
\hline LSD & 0.434 \\
\hline
\end{tabular}


Table A5. ANOVA test results for peak 1 integral.

\begin{tabular}{ccccccc}
\hline Source of Variation & SS & DoF & MS & F & $p$-Value & F Crit \\
\hline Samples & 159.160 & 17 & 9.362 & 172.451 & $1.89 \mathrm{E}-16$ & 2.232 \\
Error & 0.977 & 18 & 0.054 & & & \\
Total & 160.137 & 35 & & & & \\
\hline
\end{tabular}

Table A6. The absolute value of MSD for the parameter peak 1 integral, for the treatments investigated with the ANOVA test. For the sake of comparison, the LSD value is also reported in the table.

\begin{tabular}{cc}
\hline Samples under Comparison & MSD Absolute Value \\
\hline W50-W55 & $\mathbf{1 . 8 9 2}$ \\
W50-W60 & $\mathbf{6 . 5 2 1}$ \\
W50-S0.5 & 0.124 \\
W50-S1.5 & 0.295 \\
W50-S3 & $\mathbf{0 . 5 7 2}$ \\
W50-Y0.5 & 0.272 \\
W50-Y1.5 & $\mathbf{0 . 6 0 6}$ \\
W50-Y3 & $\mathbf{1 . 3 7 1}$ \\
CS1-CS0.5 & $\mathbf{1 . 1 4 0}$ \\
CS1-CS2 & 0.473 \\
CS1-A1 & $\mathbf{2 . 1 3 5}$ \\
CS1-C1 & $\mathbf{2 . 4 4 0}$ \\
A1-A0.5 & 0.252 \\
A1-A2 & 0.400 \\
C1-C0.5 & 0.090 \\
C1-C2 & 0.181 \\
\hline LSD & 0.489 \\
\hline
\end{tabular}

Table A7. ANOVA test results for peak 2 temperature.

\begin{tabular}{ccccccc}
\hline Source of Variation & SS & DoF & MS & F & $p$-Value & F Crit \\
\hline Samples & 1944.970 & 17 & 114.410 & 10.831 & $3.17 \mathrm{E}-06$ & 2.232 \\
Error & 190.139 & 18 & 10.563 & & & \\
Total & 2135.109 & 35 & & & & \\
\hline
\end{tabular}

Table A8. The absolute value of MSD for the parameter peak 2 temperature, for the treatments investigated with the ANOVA test. For the sake of comparison, the LSD value is also reported in the table.

\begin{tabular}{cc}
\hline Samples under Comparison & MSD Absolute Value \\
\hline W50-W55 & 0.260 \\
W50-W60 & 0.300 \\
W50-S0.5 & $\mathbf{7 . 4 8 0}$ \\
W50-S1.5 & $\mathbf{1 9 . 4 0 0}$ \\
W50-S3 & $\mathbf{2 4 . 5 9 0}$ \\
W50-Y0.5 & 0.690 \\
W50-Y1.5 & 1.280 \\
W50-Y3 & 1.290 \\
CS1-CS0.5 & 0.270 \\
CS1-CS2 & 0.970 \\
CS1-A1 & 1.760 \\
CS1-C1 & 0.330 \\
A1-A0.5 & 0.120 \\
A1-A2 & 0.30 \\
C1-C0.5 & 0.170 \\
C1-C2 & 0.370 \\
\hline LSD & 6.828 \\
\hline
\end{tabular}


Table A9. ANOVA test results for peak 2 height.

\begin{tabular}{ccccccc}
\hline Source of Variation & SS & DoF & MS & F & $p$-Value & F Crit \\
\hline Samples & 0.121 & 17 & 0.007 & 6.407 & $1.41 \mathrm{E}-04$ & 2.232 \\
Error & 0.020 & 18 & 0.001 & & & \\
Total & 0.141 & 35 & & & & \\
\hline
\end{tabular}

Table A10. The absolute value of MSD for the parameter peak 2 height, for the treatments investigated with the ANOVA test. For the sake of comparison, the LSD value is also reported in the table.

\begin{tabular}{cc}
\hline Samples under Comparison & MSD Absolute Value \\
\hline W50-W55 & 0.034 \\
W50-W60 & 0.005 \\
W50-S0.5 & $\mathbf{0 . 1 5 6}$ \\
W50-S1.5 & $\mathbf{0 . 1 3 3}$ \\
W50-S3 & 0.041 \\
W50-Y0.5 & 0.005 \\
W50-Y1.5 & 0.033 \\
W50-Y3 & 0.017 \\
CS1-CS0.5 & 0.007 \\
CS1-CS2 & 0.023 \\
CS1-A1 & $\mathbf{0 . 0 7 3}$ \\
CS1-C1 & $\mathbf{0 . 1 4 0}$ \\
A1-A0.5 & 0.013 \\
A1-A2 & 0.009 \\
C1-C0.5 & 0.023 \\
C1-C2 & 0.009 \\
\hline LSD & 0.070 \\
\hline
\end{tabular}

Table A11. ANOVA test results for peak 2 integral.

\begin{tabular}{ccccccc}
\hline Source of Variation & SS & DoF & MS & F & $\boldsymbol{p}$-Value & F Crit \\
\hline Samples & 78.522 & 17 & 4.619 & 52.857 & $6.39 \mathrm{E}-12$ & 2.232 \\
Error & 1.573 & 18 & 0.087 & & & \\
Total & 80.095 & 35 & & & & \\
\hline
\end{tabular}

Table A12. The absolute value of MSD for the parameter peak 2 integral, for the treatments investigated with the ANOVA test. For the sake of comparison, the LSD value is also reported in the table.

\begin{tabular}{cc}
\hline Samples under Comparison & MSD Absolute Value \\
\hline W50-W55 & $\mathbf{1 . 4 7 0}$ \\
W50-W60 & $\mathbf{1 . 7 0 3}$ \\
W50-S0.5 & $\mathbf{1 . 7 8 1}$ \\
W50-S1.5 & $\mathbf{4 . 4 9 6}$ \\
W50-S3 & $\mathbf{5 . 2 3 4}$ \\
W50-Y0.5 & 0.311 \\
W50-Y1.5 & 0.225 \\
W50-Y3 & 0.503 \\
CS1-CS0.5 & $\mathbf{0 . 7 4 4}$ \\
CS1-CS2 & 0.180 \\
CS1-A1 & $\mathbf{0 . 8 6 7}$ \\
CS1-C1 & $\mathbf{0 . 9 5 0}$ \\
A1-A0.5 & 0.342 \\
A1-A2 & 0.302 \\
C1-C0.5 & 0.345 \\
C1-C2 & 0.351 \\
\hline LSD & 0.621 \\
\hline
\end{tabular}




\section{References}

1. Güler, S.; Köksel, H.; Ng, P.K.W. Effects of industrial pasta drying temperatures on starch properties and pasta quality. Food Res. Int. 2002, 35, 421-427. [CrossRef]

2. Fanari, F.; Desogus, F.; Scano, E.A.; Carboni, G.; Grosso, M. The rheological properties of semolina doughs: Influence of the relative amount of ingredients. Chem. Eng. Trans. 2019, 76, 703-708.

3. Miller, R.A.; Hoseney, R.C. Role of salt in baking. Cereal Foods World 2008, 53, 4-6. [CrossRef]

4. Vittadini, E.; Clubbs, E.; Shellhammer, T.H.; Vodovotz, Y. Effect of high pressure processing and addition of glycerol and salt on the properties of water in corn tortillas. J. Cereal Sci. 2004, 39, 109-117. [CrossRef]

5. Zlatanović, S.; Ostojić, S.; Micić, D.; Rankov, S.; Dodevska, M.; Vukosavljević, P.; Gorjanović, S. Thermal behaviour and degradation kinetics of apple pomace flours. Thermochim. Acta 2019, 673, 17-25. [CrossRef]

6. Zhou, C.F.; Qian, P.; Meng, J.; Gao, S.M.; Lu, R.R. Effect of glycerol and sorbitol on the properties of dough and white bread. Cereal Chem. 2016, 93, 196-200. [CrossRef]

7. Nawrocka, A.; Szymańska-Chargot, M.; Miś, A.; Wilczewska, A.Z.; Markiewicz, K.H. Effect of dietary fibre polysaccharides on structure and thermal properties of gluten proteins-A study on gluten dough with application of FT-Raman spectroscopy, TGA and DSC. Food Hydrocoll. 2017, 69, 410-421. [CrossRef]

8. Yu, W.; Xu, D.; Zhang, H.; Guo, L.; Hong, T.; Zhang, W.; Jin, Y.; Xu, X. Effect of pigskin gelatin on baking, structural and thermal properties of frozen dough: Comprehensive studies on alteration of gluten network. Food Hydrocoll. 2020, 102, 105591. [CrossRef]

9. Lapčíková, B.; Burešová, I.; Lapčík, L.; Dabash, V.; Valenta, T. Impact of particle size on wheat dough and bread characteristics. Food Chem. 2019, 297, 124938. [CrossRef]

10. Ogawa, T.; Kobayashi, T.; Adachi, S. Prediction of pasta drying process based on a thermogravimetric analysis. J. Food Eng. 2012, 111, 129-134. [CrossRef]

11. Pacheco, M.T.; Moreno, F.J.; Moreno, R.; Villamiel, M.; Hernandez-Hernandez, O. Morphological, technological and nutritional properties of flours and starches from mashua (Tropaeolum tuberosum) and melloco (Ullucus tuberosus) cultivated in Ecuador. Food Chem. 2019, 301, 125268. [CrossRef] [PubMed]

12. Tazrart, K.; Zaidi, F.; Salvador, A.; Haros, C.M. Effect of broad bean (Vicia faba) addition on starch properties and texture of dry and fresh pasta. Food Chem. 2019, 278, 476-481. [CrossRef] [PubMed]

13. Fanari, F.; Carboni, G.; Grosso, M.; Desogus, F. Thermogravimetric analysis of different semolina doughs: Effect of mixing time and gluten content. Chem. Eng. Trans. 2019, 75, 343-348.

14. Li, J.Y.; Yeh, A.I. Relationships between thermal, rheological characteristics and swelling power for various starches. J. Food Eng. 2001, 50, 141-148. [CrossRef]

15. Leon, A.; Rosell, C.M.; De Barber, C.B. A differential scanning calorimetry study of wheat proteins. Eur. Food Res. Technol. 2003, 217, 13-16. [CrossRef]

16. Romano, A.; Di Luccia, A.; Romano, R.; Sarghini, F.; Masi, P. Microscopic and thermal characteristics of experimental models of starch, gliadins, glutenins and gluten from semolina. Chem. Eng. Trans. 2015, 43, 163-168.

17. Belitz, H.D.; Grosch, W.; Schieberle, P. Food Chemistry; Springer: Berlin, Germany, 2009; ISBN 9783540699330.

18. Goranova, Z.; Marudova, M.; Baeva, M. Influence of functional ingredients on starch gelatinization in sponge cake batter. Food Chem. 2019, 297, 124997. [CrossRef]

19. Avramenko, N.A.; Tyler, R.T.; Scanlon, M.G.; Hucl, P.; Nickerson, M.T. The chemistry of bread making: The role of salt to ensure optimal functionality of its constituents. Food Rev. Int. 2018, 34, 204-225. [CrossRef]

20. Mamat, H.; Hill, S.E. Effect of ingredients on the mass loss, pasting properties and thermal profile of semi-sweet biscuit dough. J. Therm. Anal. Calorim. 2018, 134, 1413-1428. [CrossRef]

21. Drabińska, N.; Zieliński, H.; Krupa-Kozak, U. Technological benefits of inulin-type fructans application in gluten-free products-A review. Trends Food Sci. Technol. 2016, 56, 149-157. [CrossRef]

22. Dhaka, V.; Khatkar, B.S. Effects of gliadin/glutenin and HMW-GS/LMW-GS ratio on dough rheological properties and bread-making potential of wheat varieties. J. Food Qual. 2015, 38, 71-82. [CrossRef]

23. Huault, L.; Vésinet, M.; Brogly, M.; Giampaoli, P.; Bistac, S.; Bosc, V. Adhesion of Bread Dough to Solid Surfaces Under Controlled Heating: Balance Between the Rheological and Interfacial Properties of Dough. J. Food Sci. 2019, 84, 499-506. [CrossRef] [PubMed]

24. Mohamed, A.A.; Rayas-Duarte, P. The effect of mixing and wheat protein/gluten on the gelatinization of wheat starch. Food Chem. 2003, 81, 533-545. [CrossRef] 
25. Khatkar, B.S.; Barak, S.; Mudgil, D. Effects of gliadin addition on the rheological, microscopic and thermal characteristics of wheat gluten. Int. J. Biol. Macromol. 2013, 53, 38-41. [CrossRef]

26. Fessas, D.; Schiraldi, A. Water properties in wheat flour dough. I: Classical thermogravimetry approach. Food Chem. 2001, 72, 237-244. [CrossRef]

27. Angioloni, A.; Dalla Rosa, M. Dough thermo-mechanical properties: Influence of sodium chloride, mixing time and equipment. J. Cereal Sci. 2005, 41,327-331. [CrossRef]

28. McCann, T.H.; Day, L. Effect of sodium chloride on gluten network formation, dough microstructure and rheology in relation to breadmaking. J. Cereal Sci. 2013, 57, 444-452. [CrossRef]

29. Danno, G.; Hoseney, R.C. Effect of sodium chloride and sodium dodecyl sulfate on mixograph properties. Cereal Chem. 1982, 59, 202-204.

30. Chakraborty, S.K.; Tiwari, A.; Mishra, A.; Singh, A. Rheological properties of refined wheat - millet flour based dough under thermo-mechanical stress. J. Food Sci. Technol. 2015, 52, 3044-3050. [CrossRef]

31. Ribotta, P.D.; Le Bail, A. Effect of additives on the thermo-mechanical behaviour of dough systems at sub-freezing temperatures. Eur. Food Res. Technol. 2007, 224, 519-524. [CrossRef]

32. Correa, M.J.; Ferrero, C. Thermal behaviour of wheat starch and flour at different water levels: Effect of pectins, modified celluloses and $\mathrm{NaCl}$. Starch/Staerke 2015, 67, 338-347. [CrossRef]

33. González-Soto, R.A.; Mora-Escobedo, R.; Hernández-Sánchez, H.; Sánchez-Rivera, M.; Bello-Pérez, L.A. The influence of time and storage temperature on resistant starch formation from autoclaved debranched banana starch. Food Res. Int. 2007, 40, 304-310. [CrossRef]

34. Fanari, F.; Carboni, G.; Grosso, M.; Desogus, F. Effect of the relative amount of ingredients on the thermal properties of semolina doughs. Chem. Eng. Trans. 2019, 76, 1207-1212.

35. Tronci, S.; Grosso, M.; Alvarez, J.; Baratti, R. On the global nonlinear stochastic dynamical behavior of a class of exothermic CSTRs. J. Process Control 2011, 21, 1250-1264. [CrossRef]

36. Baire, M.; Melis, A.; Lodi, M.B.; Tuveri, P.; Dachena, C.; Simone, M.; Fanti, A.; Fumera, G.; Pisanu, T.; Mazzarella, G. A wireless sensors network for monitoring the Carasau bread manufacturing process. Electronics 2019, 8, 1541. [CrossRef]

37. Baire, M.; Melis, A.; Brunolodi, M.; Fanti, A.; Mazzarella, G. Study and Design of a Wireless Sensors Network for the Optimization of Bread Manufacturing Process. In Proceedings of the 2018 26th Telecommun. Forum (TELFOR), Belgrade, Serbia, 20-21 November 2018.

38. Fanari, F.; Frau, I.; Desogus, F.; Scano, E.A.; Carboni, G.; Grosso, M. Influence of wheat varieties, mixing time and water content on the rheological properties of semolina doughs. Chem. Eng. Trans. 2019, 75, 529-534.

39. Oikonomou, N.A.; Bakalis, S.; Rahman, M.S.; Krokida, M.K. Gluten Index for Wheat Products: Main Variables in Affecting the Value and Nonlinear Regression Model. Int. J. Food Prop. 2015, 18, 1-11. [CrossRef]

40. Williams, P.; Lindhauer, M.G.; Poms, R.E.; Wehling, R.L.; Bergthaller, W.; Gaines, C.S. The joint AACC International - ICC methods harmonization project. Cereal Foods World 2008, 53, 99-102. [CrossRef]

41. Cubadda, R.; Carcea, M.; Pasqui, L.A. Suitability of the Gluten Index method for assessing gluten strength in durum-wheat and semolina. Cereal Foods World 1992, 37, 866-869.

42. Montgomery, D. Design and Analysis of Experiments; John Wiley \& Sons, Inc.: Hoboken, NJ, USA, 2013; ISBN 978-1118-14692-7.

43. Gabriele, D.; De Cindio, B.; D'Antona, P. A weak gel model for foods. Rheol. Acta 2001, 40, 120-127. [CrossRef]

44. Migliori, M.; Gabriele, D. Effect of pentosan addition on dough rheological properties. Food Res. Int. 2010, 43, 2315-2320. [CrossRef]

45. Baldino, N.; Gabriele, D.; Lupi, F.R.; De Cindio, B.; Cicerelli, L. Modeling of baking behavior of semi-sweet short dough biscuits. Innov. Food Sci. Emerg. Technol. 2014, 25, 40-52. [CrossRef]

46. Lucas, I.; Petermeier, H.; Becker, T.; Jekle, M. Definition of network types-Prediction of dough mechanical behaviour under shear by gluten microstructure. Sci. Rep. 2019, 9, 1-13. [CrossRef] [PubMed]

(C) 2020 by the authors. Licensee MDPI, Basel, Switzerland. This article is an open access article distributed under the terms and conditions of the Creative Commons Attribution (CC BY) license (http://creativecommons.org/licenses/by/4.0/). 